\title{
WestVirginiaUniversity
}

THE RESEARCH REPOSITORY @ WVU

Graduate Theses, Dissertations, and Problem Reports

2003

\section{Laboratory experiments in thermal sciences}

Christopher K. Jackson

West Virginia University

Follow this and additional works at: https://researchrepository.wvu.edu/etd

\section{Recommended Citation}

Jackson, Christopher K., "Laboratory experiments in thermal sciences" (2003). Graduate Theses, Dissertations, and Problem Reports. 1380.

https://researchrepository.wvu.edu/etd/1380

This Thesis is protected by copyright and/or related rights. It has been brought to you by the The Research Repository @ WVU with permission from the rights-holder(s). You are free to use this Thesis in any way that is permitted by the copyright and related rights legislation that applies to your use. For other uses you must obtain permission from the rights-holder(s) directly, unless additional rights are indicated by a Creative Commons license in the record and/ or on the work itself. This Thesis has been accepted for inclusion in WVU Graduate Theses, Dissertations, and Problem Reports collection by an authorized administrator of The Research Repository @ WVU. For more information, please contact researchrepository@mail.wvu.edu. 


\title{
Laboratory Experiments in Thermal Sciences
}

\author{
Christopher K. Jackson
}

Thesis Submitted to the College of Engineering and Mineral Resources at West Virginia University in partial fulfillment of the requirements for the degree of

\author{
Master of Science \\ in \\ Mechanical Engineering
}

Eric Johnson, Ph.D., Chair

John Kuhlman, Ph.D.

Gary Morris, Ph.D.

2003

Morgantown, West Virginia

Keywords: Thermodynamic Experiments

Copyright 2003 Christopher K. Jackson 


\section{ABSTRACT \\ Laboratory Experiments in Thermal Sciences}

\section{Christopher K. Jackson}

Study of the basic sciences (chemistry, biology, physics etc.) requires experimental verification to support the theory developed in the classroom. Engineering solutions are the same in their need for verification. In an academic environment this verification comes in the form of laboratory courses. The link to applications is equally important as the demonstration of theory. This is especially true for engineering disciplines due to the nature of tasks engineers are expected to successfully complete in industry. It is vital for the engineer's career that he/she can successfully apply the background theory learned in university study to real world applications.

The Department of Mechanical and Aerospace Engineering at West Virginia University had expressed an interest in increasing the number of thermodynamics and heat transfer related experiments in its thermal sciences and fluids laboratory course. Specifically, two experiments were desired. These were to include one to demonstrate the method by which enthalpy tables are created in thermodynamics, and another to demonstrate an open heat exchanger application that also loosely models an open feedwater heater.

This thesis will cover the initial design, construction, operation and analysis of these two experiments. They were designed specifically for use and demonstration in a laboratory course. They are relatively simple to operate and, with modifications, can be easily used in the time constraints of the course for which they are intended. The accuracy of the experiments is also considered. 


\section{Acknowledgements}

I would like to thank the Department of Mechanical and Aerospace Engineering for providing me with this opportunity when my initial research topic was unable to be completed in a timely manner due to reasons beyond my control. I would like to thank Drs. Kuhlman and Morris for sitting on my committee, providing me with most helpful comments in the revision process and always being available to answer questions and provide insight during all phases of this task.

I would like to thank Dr. Johnson for advising and directing me through this process. The four years (two as an undergraduate) I have spent working with him on multiple projects have provided for me a constant example of what is necessary to be successful. He has provided me an immense amount of technical insight and tremendous counsel on all matters pertaining to a successful career. Any success that I may have in the future will be due to the outstanding education that I have received at West Virginia University and Dr. Johnson is directly responsible for a large part of this education.

I would like to thank my parents for instilling in me the importance of education and the means by which to attain it. They have given me enormous amounts of support and encouragement through this process. I am very grateful to have such wonderful parents that have instilled in me the values needed to make it through this difficult and rewarding process.

Most importantly, I would like to thank my wife, Ami. I dedicate this work to her, because it is through her love and unselfishness that I have found the strength and stability necessary to complete a project such as this. I have been blessed through this entire process with her love, support and encouragement. 


\section{Table of Contents}

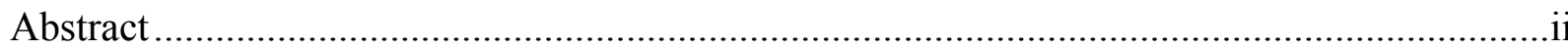

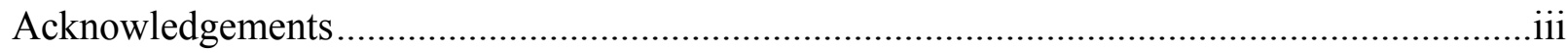

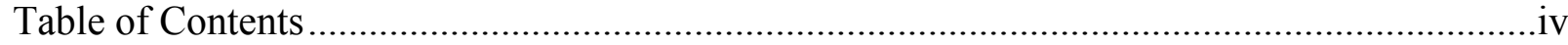

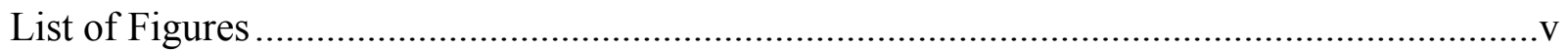

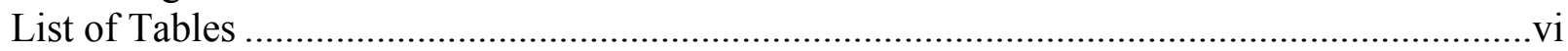

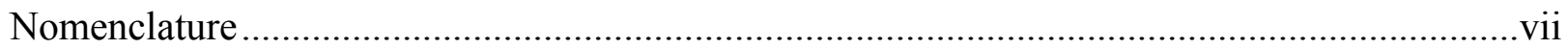

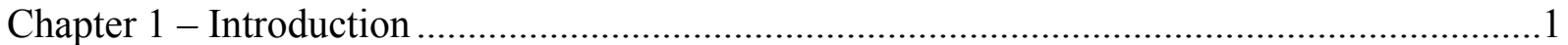

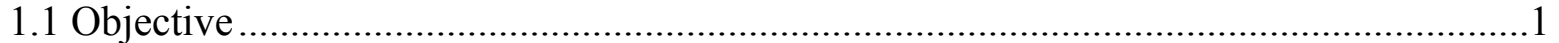

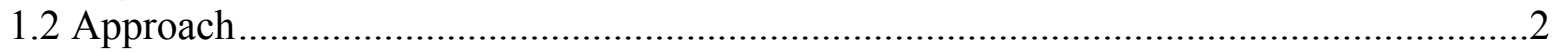

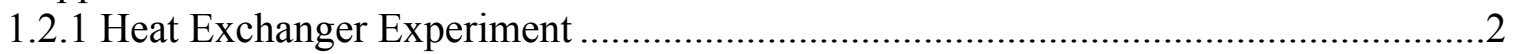

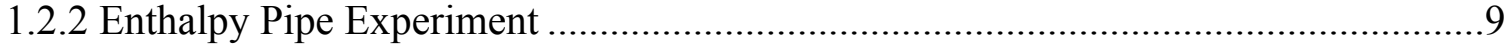

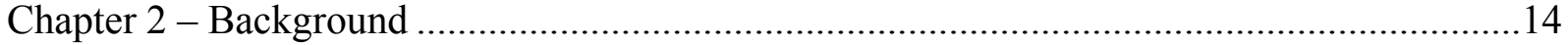

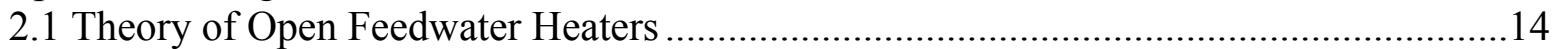

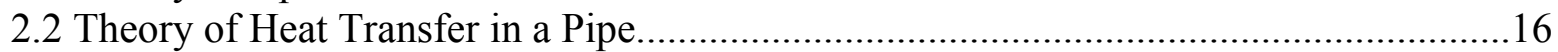

2.3 Review of Current Thermal Sciences and Fluids Laboratories ......................................22

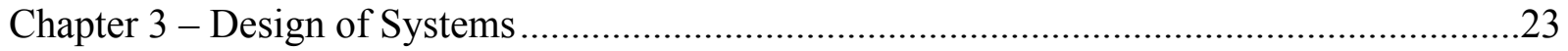

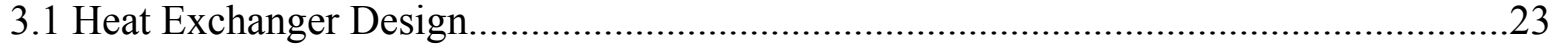

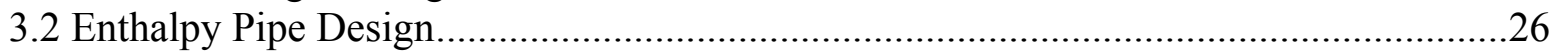

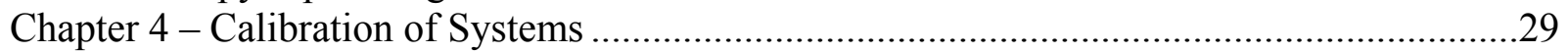

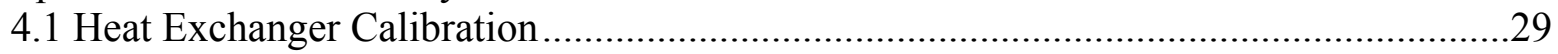

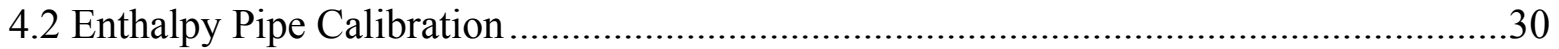

Chapter 5 - Experiment Hand-out Sheets.........................................................................

5.1 Instruction Hand-out for Heat Exchanger........................................................................

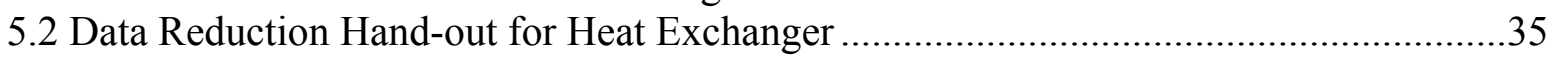

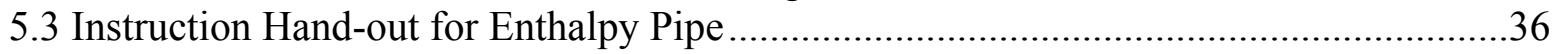

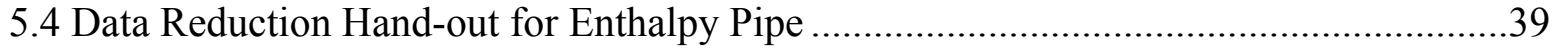

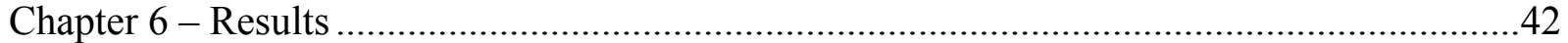

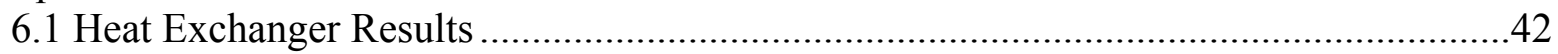

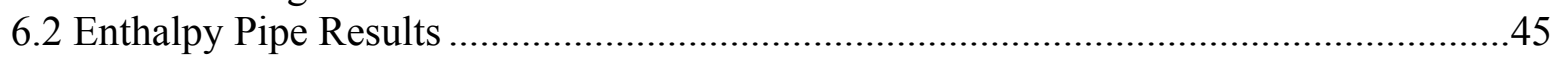

Chapter 7 - Conclusion and Recommendation....................................................................49

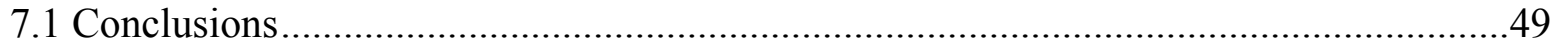

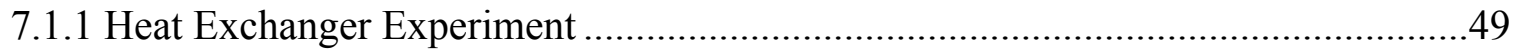

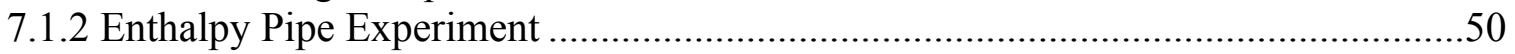

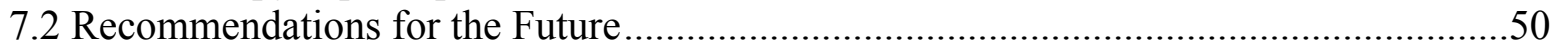

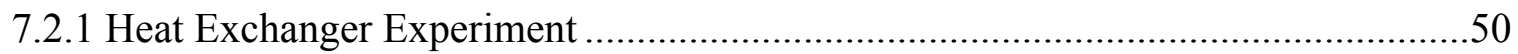

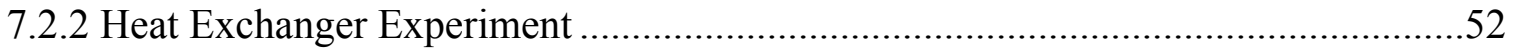

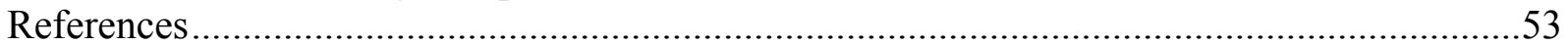

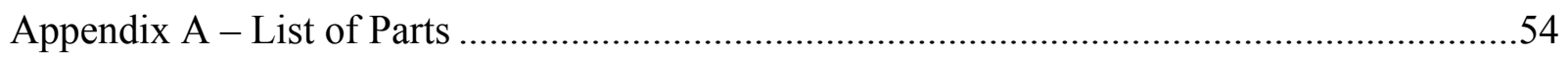

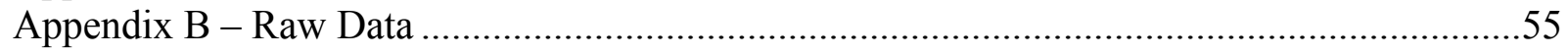

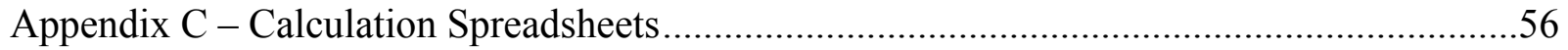

Appendix D - Uncertainty Analysis .............................................................................63

Appendix E - Flowmeter Calibration Data for Water ............................................................66

Appendix F - Flowmeter Calibration Data for Air...............................................................67 


\section{List of Figures}

Figure 1.1 - Energy Balance of Arbitrary Control Volume ...................................................4

Figure 1.2 - Schematic of a Steam Turbine Power Plant with a Feedwater Heater ..................8

Figure 1.3 - Energy Balance of Infinitesimal Subsystem...............................................

Figure 2.1 - Open Feedwater Heater Schematic .........................................................14

Figure 2.2 - Axially Sliced Pipe with Hollow Cylindrical Fluid Element ..............................17

Figure 2.3 - Force Balance on Upper Portion of Cylindrical Fluid Element .........................18

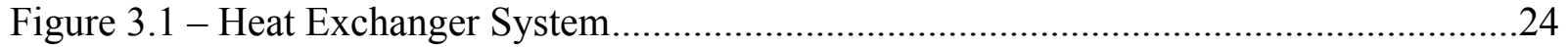

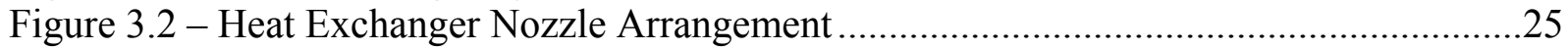

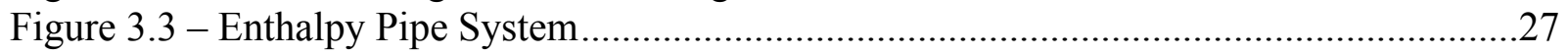




\section{$\underline{\text { List of Tables }}$}

Table 1.1 - Typical Saturated Water Data...................................................................... 13

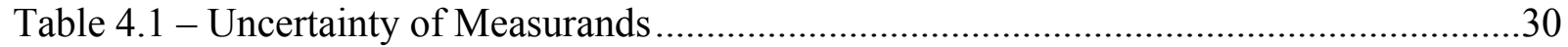

Table 6.1 - Results of Steam Enthalpy from Theory.....................................................42

Table 6.2 - Theoretical and Experimental Steam Enthalpy and Percent Error .......................43

Table 6.3 - Results of Enthalpy Change for Heated Pipe Flow ...........................................45

Table 6.4 - Enthalpy Change from Thermodynamic Tables ................................................46

Table 6.5 - Theoretical and Experimental Values for Enthalpy Change and Percent Error .....47 


\section{$\underline{\text { Nomenclature }}$}

\section{Symbols Used in Document}

\begin{tabular}{|c|c|}
\hline$A$ & Area \\
\hline$B$ & Generic Fluid Property \\
\hline$c_{p}$ & Specific Heat at Constant Pressure \\
\hline $\bar{e}$ & Energy Contained in Mass Crossing Control Surface \\
\hline$E_{s y s}$ & Initial Energy in Control Volume \\
\hline$E_{\text {tot }}$ & Total Energy in Control Volume \\
\hline$\Delta E$ & Energy Change in Control Volume \\
\hline$\varepsilon$ & Voltage \\
\hline$\eta$ & Thermal Efficiency \\
\hline$g$ & Acceleration Due to Gravity \\
\hline$h$ & Convection Heat Transfer Coefficient \\
\hline$H$ & Specific Enthalpy \\
\hline$L$ & Pipe Length \\
\hline$m$ & Mass \\
\hline$\Delta m$ & Mass Crossing Control Surface \\
\hline$\dot{m}$ & Mass Flow Rate \\
\hline$\mu$ & Viscosity \\
\hline$n$ & Outward Unit Vector \\
\hline$v$ & Specific Volume \\
\hline$\Omega$ & Resistance \\
\hline $\mathrm{p}$ & Pressure \\
\hline$P$ & Inner Pipe Perimeter \\
\hline$\dot{Q}$ & Heat Flow Rate \\
\hline$\dot{Q}_{c o n v}$ & Heat Flow Rate Due to Convection \\
\hline$\dot{Q}_{i n}$ & Heat Flow Rate into a System \\
\hline$Q_{\text {elec }}$ & Heat Flow Rate Produced by Heating Tape \\
\hline$\Delta Q$ & Heat Addition to Control Volume \\
\hline
\end{tabular}




$\begin{array}{ll}r & \text { Radial Coordinate } \\ R & \text { Radius of Inner Pipe Wall } \\ \operatorname{Re} & \text { Reynolds Number } \\ \rho & \text { Density } \\ T_{w} & \text { Local Wall Temperature } \\ T_{f} & \text { Local Bulk Fluid Temperature } \\ T_{f I} & \text { Bulk Fluid Temperature at Inlet } \\ T_{f O} & \text { Bulk Fluid Temperature at Outlet } \\ \tau & \text { Shear Stress } \\ u & \text { Specific Internal Energy } \\ U & \text { Velocity } \\ V & \text { Volume } \\ \dot{W} & \text { Work Output Rate } \\ \dot{W}_{f l o w} & \text { Rate of Work Produced by Fluid Flow } \\ \dot{W}_{n e t} & \text { Rate of Net Work Produced by a System } \\ \dot{W}_{\text {other }} & \text { Shaft, Electrical and All Other Work Rates } \\ \dot{W}_{P} & \text { Rate of Work Consumed by Pumps } \\ \dot{W}_{T} & \text { Rate of Work Produced by a Turbine } \\ \Delta W & \text { Work Output From Control Volume } \\ x & \text { Axial Coordinate } \\ z & \end{array}$




\section{Chapter 1 - Introduction}

\subsection{Objective}

Study of the basic sciences (chemistry, biology, physics etc.) requires experimental verification to back up the theory developed in the classroom. Engineering solutions are the same in their need for verification. In an academic environment this verification comes in the form of laboratory courses. While there are many applications in the study of thermal sciences and fluids that are too complex for study in a laboratory course, many of the fundamentals that form the basis of these complex applications can be easily demonstrated.

The Department of Mechanical and Aerospace Engineering at West Virginia University has expressed an interest in increasing the number of thermodynamics and heat transfer related experiments in its thermal sciences and fluids laboratory course. This thesis will cover the initial design, construction and operation of two experiments addressing this need. These experiments will cover a number of fundamentals in thermodynamics, Heat Transfer and Fluid Mechanics. In addition to demonstration of textbook theory, these experiments will cover practical engineering applications.

This link to application is equally important as the demonstration of theory. This is especially true for engineering disciplines due to the nature of tasks engineers are expected to successfully complete in industry. It is vital for the engineer's career that he/she can successfully apply the background theory learned in university study to real world applications. These experiments were designed in a manner that is consistent with this idea and will aid the development of these engineering skills.

A considerable amount of related work was previously completed on an industrial project. This work occurred over a period of 18 months, and was cut short due to reasons 
beyond the author's control. The concepts of the industrial project were then extended to the design and fabrication of the laboratory experiments described in this document.

\subsection{Approach}

Two experiments will be utilized to demonstrate fundamentals in thermodynamics, heat transfer and fluid mechanics. A heat exchanger experiment will utilize concepts including conservation of mass, conservation of energy, and an application as an open feedwater heater in a steam turbine power plant. A heated pipe flow experiment will utilize concepts including an energy balance involving heat transfer in a pipe, Reynolds number as it relates to heat transfer in a pipe, and the generation of enthalpy data as it relates to thermodynamic property tables. This thesis will be written at a level that will enable future thermal sciences and fluids laboratory instructors to reproduce any portion of the document for distribution to students.

\subsubsection{Heat Exchanger Experiment}

The Reynolds Transport Theorem states that for any fluid property, $B$, the rate of change of that property in a control volume is defined by the equation (1.1)

$$
\frac{d}{d t}\left(B_{\text {sys }}\right)=\int_{C V} \frac{\partial}{\partial t}(\beta \rho) d V+\int_{C S} \beta \rho(U \cdot n) d A
$$

where $\beta=\frac{d B}{d m}$ and is the amount of $B$ per unit mass present in any small portion of the fluid.

The density of the fluid in any small portion of the fluid is represented by $\rho, n$ is the outward unit vector normal to the area $d A, U$ is the velocity of the fluid crossing the control surface through the area $d A$ and $V$ is the volume contained in the control volume. The first term on the right hand side of equation (1.1) represents the rate of accumulation of $B$ within the control volume due to any change in density of the fluid. The second term on the right hand side represents any increase or decrease in $B$ due to fluid crossing the control surface. 
If the property of interest is mass, $m$, then $\beta$ is equal to 1 and equation (1.1) simplifies to equation (1.2).

$$
\frac{d}{d t}\left(m_{s y s}\right)=\int_{C V} \frac{\partial \rho}{\partial t} d V+\int_{C S} \rho(U \cdot n) d A
$$

For a system operating in steady state with no creation or destruction of mass the following assumptions can be made.

$$
\frac{d}{d t}\left(m_{s y s}\right)=0 \quad \frac{\partial \rho}{\partial t}=0
$$

These assumptions simplify (1.2) to (1.4).

$$
\int_{C S} \rho(U \cdot n) d A=0
$$

For a system with a number of inlets and outlets equation (1.4) can be represented by (1.5).

$$
\sum_{i}\left(\rho_{i} U_{i} A_{i}\right)_{\text {out }}-\sum_{j}\left(\rho_{j} U_{j} A_{j}\right)_{\text {in }}=0
$$

The quantity in parenthesis is the definition of mass flow rate passing through a cross-sectional area $A$. Equation (1.5) can then be rewritten as (1.6).

$$
\sum_{i}\left(\dot{m}_{i}\right)_{\text {in }}=\sum_{j}\left(\dot{m}_{j}\right)_{\text {out }}
$$

Where $\dot{m}$ is shorthand for the time derivative of mass, or mass flow rate, $\frac{d m}{d t}$. Equation (1.6) states that the sum of the mass flow rates into the control volume must equal the sum of the mass flow rates out of the control volume for steady flow. This concept will be used to account for all of the mass entering and exiting the heat exchanger.

Figure 1.1 shows an arbitrary control volume with heat addition, $\Delta Q$, work output, $\Delta W$, and mass entering and exiting the control volume. This is a general model of an open thermodynamic system, the system being defined as the control volume. To develop an energy 
balance for this system it is convenient to imagine the system at a time $t$ before any heat, work, or mass has crossed the system boundaries.

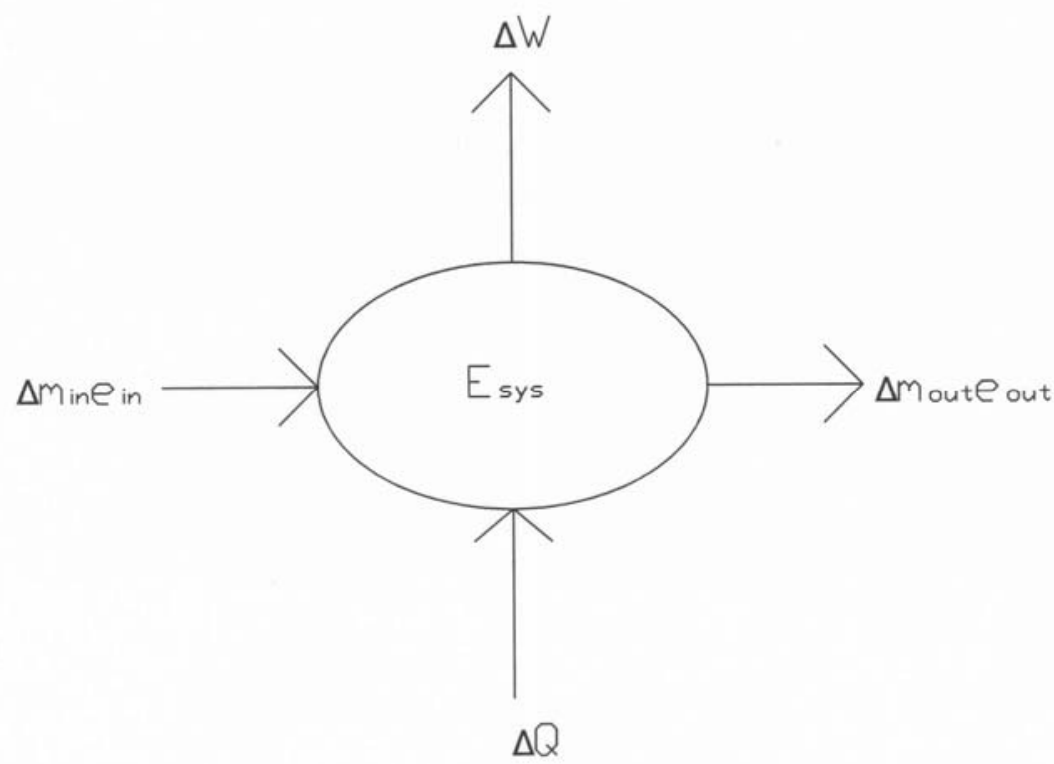

Figure 1.1 - Energy Balance of Arbitrary Control Volume

The total energy contained by the control volume is the following.

$$
E_{t o t}=E_{s y s}
$$

A short time thereafter, $t+\Delta t$, heat, work and mass have crossed the system boundary and the total energy contained in the control volume is defined by the following.

$$
E_{\text {tot }}=E_{\text {sys }}+\Delta Q-\Delta W+(\Delta m \bar{e})_{\text {in }}-(\Delta m \bar{e})_{\text {out }}
$$

The total change in energy between these two times can be obtained by subtracting the system energy at $t+\Delta t$ from that at $t$. The energy contained in the system initially cancels out and the change in energy is described by the following. 


$$
\Delta E=\Delta Q-\Delta W+(\Delta m \bar{e})_{\text {in }}-(\Delta m \bar{e})_{\text {out }}
$$

Equation (1.9) explains the change in energy in the system for only a small amount of time $\Delta t$. For continuous analysis of an open system it is convenient to have the terms in equation (1.9) as rates, which can be accomplished by dividing (1.9) by $\Delta t$ and taking the limit as $\Delta t$ approaches zero.

$$
\operatorname{Lim}_{\Delta t \rightarrow 0}\left(\frac{\Delta E}{\Delta t}=\frac{\Delta Q}{\Delta t}-\frac{\Delta W}{\Delta t}+\bar{e}_{\text {in }} \frac{\Delta m_{\text {in }}}{\Delta t}-\bar{e}_{\text {out }} \frac{\Delta m_{\text {out }}}{\Delta t}\right)
$$

Equation (1.10) then becomes (1.11).

$$
\frac{d E}{d t}=\dot{Q}-\dot{W}+\dot{m}_{\text {in }} e_{\text {in }}-\dot{m}_{\text {out }} e_{\text {out }}
$$

The energy term, $\bar{e}$, is an average value, however with $\Delta t$ approaching zero it becomes the instantaneous value, $e$. The energy term associated with the entering and exiting mass contains terms for the specific internal energy, $u$, kinetic energy, $\frac{U^{2}}{2}$, and gravitational potential energy, $g z$. With the energy terms expanded equation (1.11) becomes (1.12).

$$
\frac{d E}{d t}=\dot{Q}-\dot{W}+\dot{m}_{\text {in }}\left(u+\frac{U^{2}}{2}+g z\right)_{\text {in }}-\dot{m}_{\text {out }}\left(u+\frac{U^{2}}{2}+g z\right)_{\text {out }}
$$

It is convenient for thermodynamic analysis to split the work term into two parts, the flow work that occurs at the entrance and exit points of the system and all other work (shaft, electrical, etc).

$$
\dot{W}_{\text {tot }}=\dot{W}_{\text {flow }}+\dot{W}
$$

The rate of flow work can be written as force acting on a moving surface multiplied by its velocity, $U$. It represents the work to push the fluid in or out of the control volume. Writing the 
flow work term in this manner, with the force written as pressure, $p$, multiplied by area, $A$, results in (1.14).

$$
\dot{W}_{\text {flow }}=(p A) U
$$

The mass flow rate can be written as (1.15)

$$
\dot{m}=\frac{A U}{v}
$$

where $v$ is the specific volume (inverse of density) of the fluid. Rewriting equation (1.15) as

$$
A U=\dot{m} v
$$

and then substituting into equation (1.14) results in a convenient expression for flow work.

$$
\dot{W}_{\text {flow }}=\dot{m} p v
$$

Substituting both work terms into equation (1.12) results in the following equation.

$$
\begin{aligned}
& \frac{d E}{d t}=\dot{Q}-\dot{W}+\dot{m}_{\text {in }} p_{\text {in }} v_{\text {in }}-\dot{m}_{\text {out }} p_{\text {out }} v_{\text {out }}+ \\
& \dot{m}_{\text {in }}\left(u+\frac{U^{2}}{2}+g z\right)_{\text {in }}-\dot{m}_{\text {out }}\left(u+\frac{U^{2}}{2}+g z\right)_{\text {out }}
\end{aligned}
$$

It is convenient to combine all of the mass terms and rearrange as in equation (1.19).

$$
\begin{aligned}
& \frac{d E}{d t}=\dot{Q}-\dot{W}+\dot{m}_{\text {in }}\left(u+p v+\frac{U^{2}}{2}+g z\right)_{\text {in }}- \\
& \dot{m}_{\text {out }}\left(u+p v+\frac{U^{2}}{2}+g z\right)_{\text {out }}
\end{aligned}
$$

The thermodynamic property specific enthalpy, $H$, is defined as the sum of specific internal energy and flow work.

$$
H=u+p v
$$

Making use of this property, equation (1.19) can be rewritten. 


$$
\frac{d E}{d t}=\dot{Q}-\dot{W}+\dot{m}_{\text {in }}\left(H+\frac{U^{2}}{2}+g z\right)_{\text {in }}-\dot{m}_{\text {out }}\left(H+\frac{U^{2}}{2}+g z\right)_{\text {out }}
$$

It is common for engineering systems to have more than one entrance and/or exit. To account for this it is convenient to add summations for the inlet and outlet terms.

$$
\begin{aligned}
& \frac{d E}{d t}=\dot{Q}-\dot{W}+\sum_{i} \dot{m}_{\text {in }}\left(H+\frac{U^{2}}{2}+g z\right)_{\text {in }}- \\
& \sum_{j} \dot{m}_{\text {out }}\left(H+\frac{U^{2}}{2}+g z\right)_{\text {out }}
\end{aligned}
$$

This form of the conservation of energy equation for open systems will be used later in Chapter 2 for further analysis of the systems presented.

The heat exchanger described in this thesis involves the mixing of steam and a tap water temperature water spray. The water spray condenses the steam and the mixture exits the heat exchanger as a heated liquid water. This process closely resembles the operation of an open feedwater heater in a steam power plant. Figure 1.2 shows a typical steam power cycle containing an open feedwater heater. Steam enters the feedwater heater at location 2, liquid water enters at location 1 and the exit stream is location 3 . The major difference between the model and an operational feedwater heater is the pressure at which the heat exchanger operates. In power plant operation the steam entering the chamber is extracted from the turbine at an intermediate point in the steam expansion process. The liquid with which it is mixed has passed entirely through the turbine and through a condenser. The extracted steam has not fully expanded and is at a higher pressure than that of the liquid with which it mixes. Therefore, the liquid must be pumped up to the same pressure as the steam before it enters the feedwater heater. The model will operate slightly above atmospheric pressure. 
Integrating an open feedwater heater into a steam power cycle will add some cost and complexities. However, the benefit of increased efficiency for the cycle outweighs these complications. The goal of the open feedwater heater is to introduce a heated liquid to the boiler instead of a lower temperature liquid. This requires less fuel to be consumed for the purpose of generating steam. The power output of the turbine will be slightly reduced due to the fact that some steam is extracted, however this is small compared to the reduction of fuel, which results in the increase in thermal efficiency.

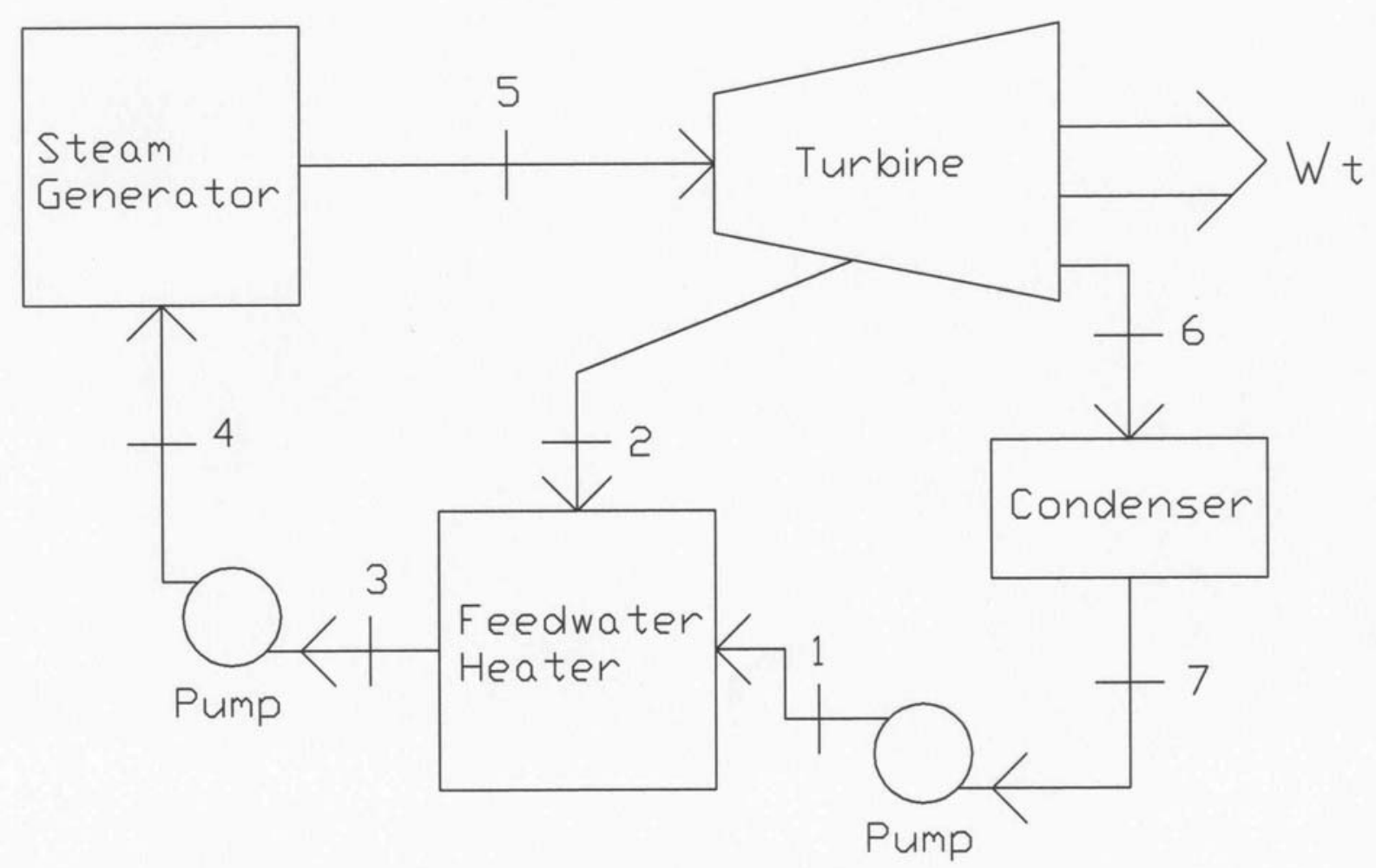

Figure 1.2 - Schematic of a Steam Turbine Power Plant with a Feedwater Heater 


\subsubsection{Enthalpy Pipe}

Figure 1.3 shows an infinitesimally small subsystem of the heated pipe flow. The subsystem length is $\Delta x$. The steady state energy balance consists of heat transfer to the fluid from the pipe wall and the energy associated with the mass entering and exiting the subsystem. This is similar to the energy balance associated with the heat exchanger. The energy balance analysis results in the following equation.

$$
\left.\dot{m} H)_{x}-\dot{m} H\right)_{x+\Delta x}+\dot{Q}_{c o n v}=0
$$

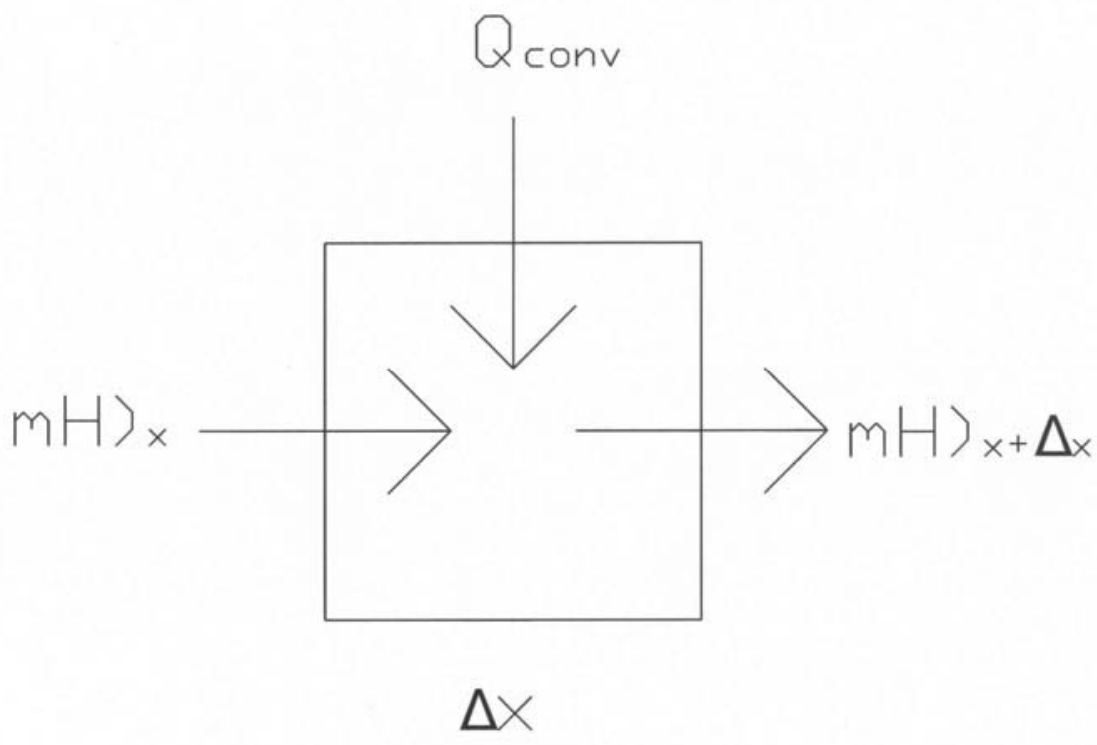

Figure 1.3 - Energy Balance of Infinitesimal Subsystem

The convection term can be replaced by substitution of Newton's Law of Cooling.

$$
\dot{Q}_{\text {conv }}=h A\left(T_{w}-T_{f}\right)
$$

where $h$ is a constant of proportionality referred to as convection heat transfer coefficient, $T_{w}$ is the local wall temperature, and $T_{f}$ is the local (bulk) fluid temperature. The area across which 
heat transfer takes place, $A$, can be replaced by the inner perimeter of the pipe, $P$, multiplied by the length of the subsystem, $\Delta x$.

$$
\dot{Q}_{\text {conv }}=h P \Delta x\left(T_{w}-T_{f}\right)
$$

Substituting (1.25) into (1.23) results in the following equation.

$$
\left.\dot{m} H)_{x}-\dot{m} H\right)_{x+\Delta x}+h P \Delta x\left(T_{w}-T_{f}\right)=0
$$

Equation (1.26) can be rewritten as

$$
\frac{\left.\dot{m} H)_{x}-\dot{m} H\right)_{x+\Delta x}}{\Delta x}=-h P\left(T_{w}-T_{f}\right)
$$

taking the limit as $\Delta x$ approaches zero results in equation (1.28).

$$
\dot{m} \frac{d H}{d x}=h P\left(T_{w}-T_{f}\right)
$$

Specific enthalpy is a function of both temperature and pressure, $H(T, P)$. Employing the chain rule to differentiate specific enthalpy with respect to $x$ results in equation (1.29).

$$
\frac{d H}{d x}=\left(\frac{\partial H}{\partial T}\right)_{p} \frac{d T}{d x}+\left(\frac{\partial H}{\partial p}\right)_{T} \frac{d p}{d x}
$$

The change in specific enthalpy with respect to temperature is defined as the specific heat at constant pressure of a substance.

$$
c_{p}=\left(\frac{\partial H}{\partial T}\right)_{p}
$$

The change in specific enthalpy with respect to pressure is essentially zero for the fluids employed in these experiments.

$$
\left(\frac{\partial H}{\partial p}\right)_{T}=0
$$


The specific enthalpy differential can be written in terms of fluid temperature according to the following.

$$
\frac{d H}{d x}=c_{p} \frac{d T_{f}}{d x}
$$

Here $c_{p}$ is the specific heat at constant pressure of the fluid based on the average temperature across the differential fluid element, $\left(T_{f}\right)$. Equation (1.28) can be rewritten as the following.

$$
\dot{m} c_{p} \frac{d T_{f}}{d x}=h P\left(T_{w}-T_{f}\right)
$$

Equation (1.33) can be used to determine the fluid temperature profile when the axial wall temperature profile is known or assumed. However, (1.33) must first be solved for fluid temperature and have a boundary condition applied to it. It is usually convenient to apply a boundary condition of known fluid temperature at the pipe entrance.

The heat transfer coefficient in a pipe flow is dependent on many factors, some of which are fluid properties, pipe geometry and surface roughness. However, in most typical pipe flows the strongest indicator of order of the heat transfer coefficient is a dimensionless quantity called Reynolds number. Reynolds number is defined according to the following equation.

$$
\operatorname{Re}=\frac{\rho U L}{\mu}
$$

Where $\rho$ is the fluid density, $U$ is the mean (bulk) fluid velocity, $\mu$ is the fluid viscosity and $L$ is the characteristic length of the specific problem under investigation. The characteristic length for a pipe flow is the inside diameter of the pipe, $D$. Reynolds number for a pipe flow is written as the following.

$$
\operatorname{Re}_{D}=\frac{\rho U D}{\mu}
$$


The subscript $D$ denotes that the characteristic length is the pipe diameter. Reynolds number can also be written in terms of the mass flow rate (1.36).

$$
\operatorname{Re}_{D}=\frac{4 \dot{m}}{\pi \mu D}
$$

For any fluid flow there are three possible flow regimes. For low Reynolds number flows the flow regime is laminar. Laminar fully developed flow assumes a parabolic velocity profile in pipes with a maximum velocity at the centerline of the pipe and velocity decreasing proportionately with the square of the distance measured from the centerline. Flows with high Reynolds numbers are in the turbulent regime. Turbulent flow experiences random fluctuations of velocity, but when averaged over time velocity is nearly constant. In a turbulent pipe flow, the average velocity is constant over most of the flow area and then reduces to zero sharply near the pipe walls. At some intermediate flow regime between laminar and turbulent flow, the flow is in a transitional regime. Transitional flow can be described as laminar-like with occasional random fluctuations. In pipe flow transition may occur between Reynolds numbers of 2300 to 3200.

The characteristics of a pipe flow are determined by the flow regime it is operating in. Heat transfer analysis is greatly dependent on whether the flow is laminar or turbulent. In a heated pipe flow heat transfer is greatly increased when the flow is turbulent. Determining the pressure loss in a pipe flow is also dependent on the flow regime. This is significant because the amount of pump work needed to drive the flow can be reduced by selecting the appropriate flow conditions.

Thermodynamic analysis of a problem often requires that the analyzer retrieve property data of common substances (water, refrigerant, gases, etc) from property tables. These tables can be found in the back of almost any thermodynamics textbook. It is necessary to know the 
technique for retrieving this data in order to solve problems; however, the method in which this data is compiled is often forgotten. Table 1.1 shows the layout of a typical textbook property table for saturated water. The quantities related to energy contained in the substance (specific internal energy and specific enthalpy) have very precise values, however these values will vary depending upon which textbook you are viewing. This is because these property values are based on some chosen reference temperature at which the properties are assigned a value of zero. Energy is added, temperature and pressure change is recorded and a property value is assigned for those conditions for the substance. Therefore, these properties are not suitable for stand alone values.

\begin{tabular}{|c|c|c|c|c|}
\hline Temp & \multicolumn{2}{|c|}{$\begin{array}{c}\text { Internal Energy } \\
(\mathbf{k J / k g})\end{array}$} & \multicolumn{2}{c|}{$\begin{array}{c}\text { Enthalpy } \\
(\mathbf{k J} / \mathbf{k g})\end{array}$} \\
\hline${ }^{\circ} \mathbf{C}$ & $\begin{array}{c}\text { Sat. } \\
\text { Liquid }\end{array}$ & $\begin{array}{c}\text { Sat. } \\
\text { Vapor }\end{array}$ & $\begin{array}{c}\text { Sat. } \\
\text { Liquid }\end{array}$ & $\begin{array}{c}\text { Sat. } \\
\text { Vapor }\end{array}$ \\
\hline 10 & 42.00 & 2389.2 & 42.01 & 2519.8 \\
\hline 11 & 46.20 & 2390.5 & 46.20 & 2521.6 \\
\hline 12 & 50.41 & 2391.9 & 50.41 & 2523.4 \\
\hline 13 & 54.60 & 2393.3 & 54.60 & 2525.3 \\
\hline 14 & 58.79 & 2394.7 & 58.80 & 2527.1 \\
\hline 15 & 62.99 & 2396.1 & 62.99 & 2528.9 \\
\hline 16 & 67.18 & 2397.4 & 67.19 & 2530.8 \\
\hline 17 & 71.38 & 2398.8 & 71.38 & 2542.6 \\
\hline
\end{tabular}

Table 1.1 - Typical Saturated Water Data

They can only be used in difference calculations. It is not possible to say enthalpy is equal to an absolute number at a certain temperature and pressure. It is possible, however, to say that the difference in enthalpy between state one and state two is a certain value. This value will not usually vary with each textbook. The enthalpy pipe experiment will demonstrate this method of generating enthalpy tables. 


\section{Chapter 2 - Background}

\subsection{Theory of Open Feedwater Heaters}

Figure 2.1 shows a schematic of the open feedwater heater model. The numbers assigned to the inlets and outlets correspond to the numbers in Figure 1.2. This allows visualization of where this model would fit in an actual power plant cycle. The first step in analyzing an open

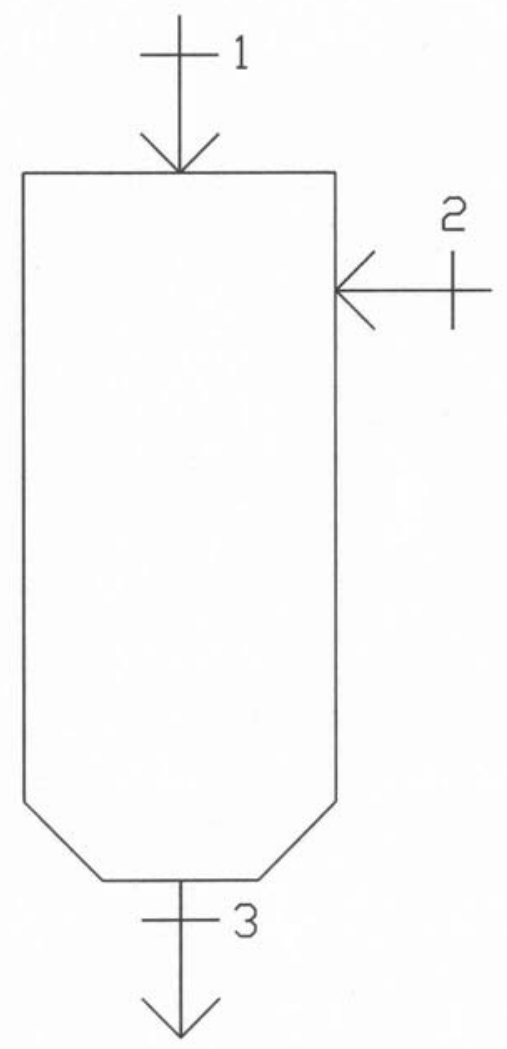

Figure 2.1 - Open Feedwater Heater Schematic

system is applying conservation of mass to the system. Applying equation (1.6) to the open

$$
\sum_{i}\left(\dot{m}_{i}\right)_{\text {in }}=\sum_{j}\left(\dot{m}_{j}\right)_{\text {out }}
$$


feedwater heater model results in equation (2.1).

$$
\dot{m}_{1}+\dot{m}_{2}=\dot{m}_{3}
$$

The next step in analysis of the open feedwater heater model is applying conservation of energy to the system. Equation (1.22) represents the conservation of energy principle for an

$$
\begin{aligned}
& \frac{d E}{d t}=\dot{Q}-\dot{W}+\sum_{i} \dot{m}_{\text {in }}\left(H+\frac{U^{2}}{2}+g z\right)_{\text {in }}- \\
& \sum_{j} \dot{m}_{\text {out }}\left(H+\frac{U^{2}}{2}+g z\right)_{\text {out }}
\end{aligned}
$$

open system. The open feedwater heater model is well insulated, there is no work produced by any means other than flow, and the system is analyzed only after it has reached steady state operation, therefore there is no rate of energy change in the system. This leads to the following assumptions (2.2).

$$
\begin{aligned}
& \frac{d E}{d t}=0 \\
& \dot{Q}=0 \\
& \dot{W}=0
\end{aligned}
$$

Equation (1.22) is then simplified to equation (2.3).

$$
\begin{aligned}
& \dot{m}_{1}\left(H_{1}+\frac{U_{1}^{2}}{2}+g z_{1}\right)+\dot{m}_{2}\left(H_{2}+\frac{U_{2}^{2}}{2}+g z_{2}\right)= \\
& \cdot \dot{m}_{3}\left(H_{3}+\frac{U_{3}^{2}}{2}+g z_{3}\right)
\end{aligned}
$$

The differences in kinetic and potential energies entering and exiting the heat exchanger are negligible when compared to the energy associated with the enthalpy of the streams. Neglecting these terms simplifies equation (2.3) to (2.4).

$$
\dot{m}_{1} H_{1}+\dot{m}_{2} H_{2}=\dot{m}_{3} H_{3}
$$


Equation (2.4) accounts for all of the energy entering and exiting the open feedwater heater.

Therefore, any calculations involving energy will require equation (2.4).

Thermal efficiency of a system is defined as the net work produced by the system divided by the heat input required by the system to produce this work. This concept is represented by equation (2.5).

$$
\eta=\frac{\dot{W}_{n e t}}{\dot{Q}_{\text {in }}}
$$

The net work produced by the steam turbine cycle in Figure 1.2 is the amount of work produced by the turbine subtracted by the work consumed by the pumps. Equation (2.5) then becomes equation (2.6).

$$
\eta=\frac{\dot{W}_{T}-\dot{W}_{P}}{\dot{Q}_{i n}}
$$

The inclusion of an open feedwater heater in the system significantly reduces the amount of heat required to produce the steam used to drive the turbine. The reduction in work produced by the turbine is small compared to the reduction of heat lost to the condenser and leads to an increased efficiency as calculated by equation (2.6).

\subsection{Theory of Heat Transfer in a Pipe}

The most common application of a system involving heat transfer in a pipe flow is to transfer thermal energy from a heat source surrounding the pipe to the fluid inside of the pipe. An example would be pipes in a closed heat exchanger in which the two fluids involved do not mix. It is also common to heat a pipe flow that has a temperature elevated from its surroundings. This occurs in engine emissions testing and its purpose is to keep the exhaust gases above a critical temperature so that the vapor in the gases does not condense and create instrumentation 
errors. The purpose of the heated flow in this experiment is to demonstrate a change in enthalpy that accompanies a change in temperature of the fluid.

The first task necessary in analysis of a heated pipe flow is an investigation of the fluid mechanics involved. As discussed in Chapter 1, flow conditions dictate one of the following flow regimes: laminar, transitional or turbulent. The conditions selected for this experiment place the flow in the laminar regime. Therefore, the fluid mechanics discussion will be limited to such.

Figure 2.2 shows a typical fluid element in a pipe that has been sliced along the axial direction, $x$. The fluid element is a hollow cylinder of length $\Delta x$ and thickness $\Delta r$. The velocity

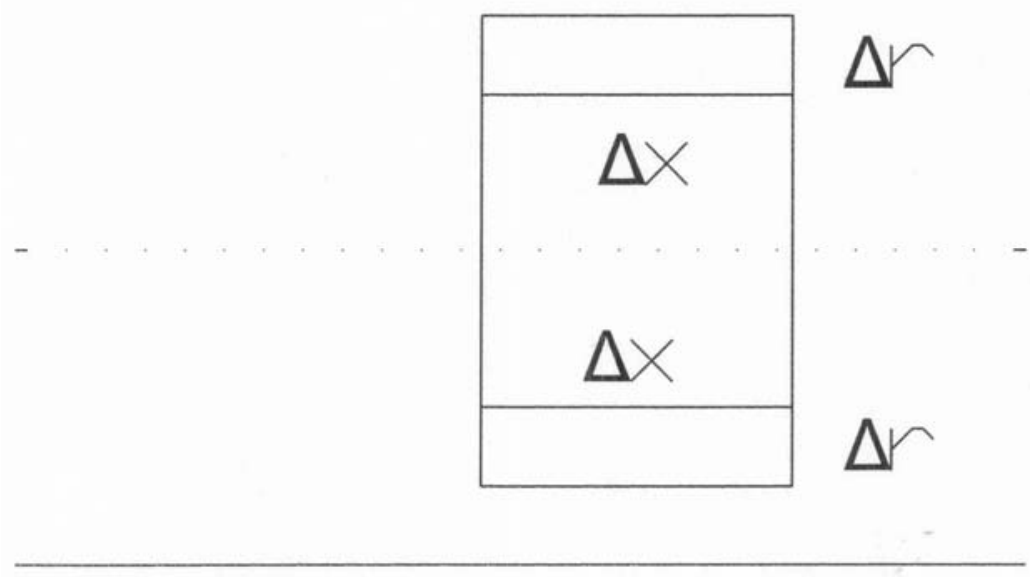

Figure 2.2 - Axially Sliced Pipe with a Hollow Cylindrical Fluid Element

distribution in a pipe flow can be developed using a force balance on the fluid element. Figure 2.3 shows this force balance on the upper portion of the visible element in the slice. Although this element looks rectangular, it loops into and out of the page to form a hollow cylinder. There is no pressure force acting in the radial direction because the pressure gradient is zero in that 
direction. There is no shear stress acting in the radial direction because the velocity distribution is constant in the axial direction. The force resulting from shear stress applied to the cylinder

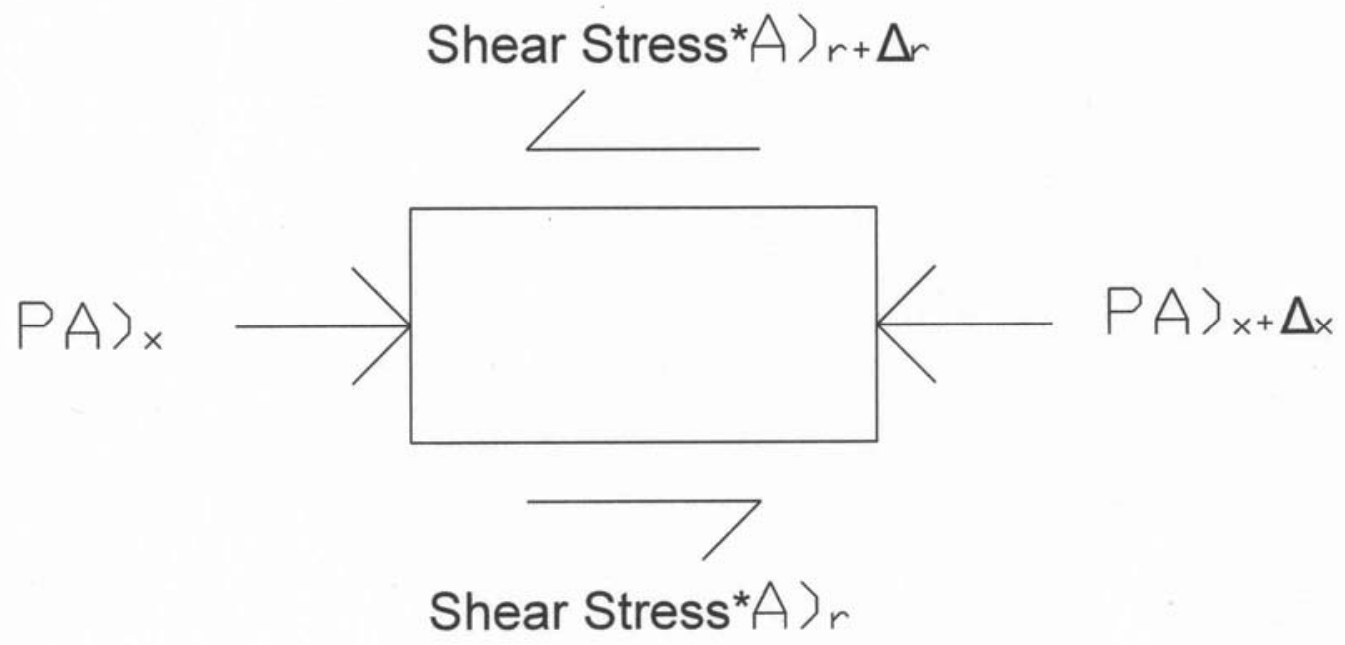

Figure 2.3 - Force Balance on Upper Portion of Cylindrical Fluid Element

surface is defined in equation (2.7).

$$
\text { ShearStress * } A=-\mu \frac{d U}{d r} 2 \pi r \Delta x
$$

The shear stress portion is defined by the definition of a Newtonian Fluid which is illustrated by equation (2.8), where $\mu$ is fluid viscosity.

$$
\text { ShearStress }=\tau=-\mu \frac{d U}{d r}
$$

The force on the fluid element due to pressure force is defined in equation (2.9).

$$
P A=2 \pi r \Delta r p
$$

Setting the sum of the force terms equal to zero results in equation (2.10).

$$
\begin{aligned}
& (2 \pi r \Delta r p)_{x}-(2 \pi r \Delta r p)_{x+\Delta x}+\left(-\mu \frac{d U}{d r} 2 \pi r \Delta x\right)_{r}- \\
& \left(-\mu \frac{d U}{d r} 2 \pi r \Delta x\right)_{r+\Delta r}=0
\end{aligned}
$$


Dividing equation (2.10) by $2 \pi \Delta r \Delta x$ results in (2.11).

$$
\frac{(r p)_{x}-(r p)_{x+\Delta x}}{\Delta x}-\frac{\left(r \mu \frac{d U}{d r}\right)_{r}-\left(r \mu \frac{d U}{d r}\right)_{r+\Delta r}}{\Delta r}=0
$$

Taking the limit as $\Delta x$ and $\Delta r$ are allowed to approach zero results in (2.12).

$$
\frac{d}{d r}\left(r \mu \frac{d U}{d r}\right)=r \frac{d p}{d x}
$$

The fluid velocity, $U$, is a function of only $r$ because it is fully developed and does not change along the axial pipe direction. Equation (2.12) can be solved by integration because the pressure gradient, $\frac{d P}{d x}$, is a constant. Integrating $(2.12)$ results in (2.13).

$$
r \mu \frac{d U}{d r}=\frac{r^{2}}{2} \frac{d p}{d x}+C_{1}
$$

The constant of integration, $C_{1}$, can be solved for by applying the following symmetry boundary condition.

$$
\frac{d U}{d r}=0 \text { at } r=0
$$

Substituting equation (2.14) into (2.13) results in the constant equal to zero. Integrating (2.13), taking into account the result of the first boundary condition, results in equation (2.15).

$$
U=\frac{r^{2}}{4 \mu} \frac{d p}{d x}+C_{2}
$$

Applying a no slip condition at the wall (2.16) results in the solution of $C_{2}(2.17)$.

$$
\begin{aligned}
& U=0 \text { at } r=R \\
& C_{2}=-\frac{R^{2}}{4 \mu} \frac{d p}{d x}
\end{aligned}
$$


Where $R$ is the radius of the inner pipe wall. Substituting this constant into (2.15) and rearranging the terms results in (2.18) which describes exactly the velocity profile in the pipe.

$$
U=\frac{R^{2}}{4 \mu}\left(-\frac{d p}{d x}\right)\left[1-\left(\frac{r}{R}\right)^{2}\right]
$$

Equation (1.33) was the result of an energy balance in a chunk of fluid in a pipe flow with a constant heat flux at the wall. The right side of equation (1.33) represents the rate of

$$
\dot{m} c_{p} \frac{d T_{f}}{d x}=h P\left(T_{w}-T_{f}\right)
$$

energy added to the flow from the heat flux. For heat flux to be constant the right side of (1.33) must be constant. For a fixed diameter pipe and steady state flow condition the only terms that are not constants on the right side are the fluid and wall temperatures. This means that the difference between the two temperatures must be constant. Upon examination of the left side of equation (1.33) it is obvious that, under the stated conditions, every term on that side is constant. The conclusion can be made that the fluid temperature gradient is equal to a constant.

$$
\frac{d T_{f}}{d x}=c
$$

Integrating equation (2.19) leads to (2.20).

$$
T_{f}=c_{1} x+c_{2}
$$

The boundary conditions needed to solve for the constants in (2.20) are as follows.

$$
\begin{aligned}
& T_{f}=T_{f l} \text { at } x=0 \\
& T_{f}=T_{f O} \text { at } x=L
\end{aligned}
$$

Equation (2.20) then becomes (2.23).

$$
T_{f}=\left(T_{f O}-T_{f I}\right) \frac{x}{L}+T_{f I}
$$


As assumed in equation (2.19) the fluid temperature gradient is constant.

$$
\frac{d T_{f}}{d x}=\frac{T_{f O}-T_{f I}}{L}
$$

Substituting equations (2.23) and (2.24) into equation (1.33) and solving for the pipe wall temperature results in (2.25).

$$
T_{w}=\left(T_{f O}-T_{f l}\right)\left[\frac{x}{L}+\frac{\dot{m} c_{p}}{h P L}\right]+T_{f l}
$$

It is possible to make a few observations about a pipe flow by examining equation (2.25). The convection heat transfer coefficient, $h$, tells a large part of the story of such a system. Let $x$ be a fixed point anywhere along the pipe between the inlet and outlet. The only remaining variables in (2.25) are the heat transfer coefficient and the mass flow rate, $\dot{m}$. The heat transfer coefficient and mass flow rate are related however. As the mass flow rate is increased the heat transfer coefficient is increased as a result. The maximum mass flow rate is finite and is determined by the pipe geometry, pressure upstream created by a pump and other factors. Imagine that it is possible for the heat transfer coefficient to approach infinity. The equation for the wall temperature would equal the equation for the fluid temperature. This perfectly illustrates the meaning of the heat transfer coefficient. With an infinite heat transfer coefficient the temperature difference between the wall and fluid would be infinitesimally small. However, for flow conditions that are realistic the wall temperature will be above that of the fluid. The magnitude of the temperature difference depends exclusively on the heat transfer coefficient which depends in large part on the mass flow rate.

Equations (2.19) through (2.25) are valid only for a fully developed pipe flow. In a pipe flow that undergoes a change in pipe diameter immediately prior to heating it is important to 
examine entrance effects that may affect the system's heat transfer characteristics. The thermal entrance length, $L_{e h}$, can be defined as the distance required for the flow to reach steady flow heat transfer conditions. This distance is dependent on the Reynolds number of the flow and the Prandtl number of the flow. The Prandtl number is a dimensionless parameter that relates thermal and physical properties of the fluid. The entry length of a laminar flow can be determined by (2.26) (Mills, 1995).

$$
L_{e h}=0.017 D \operatorname{Re}_{D} \operatorname{Pr}
$$

\subsection{Review of Current Thermal Sciences and Fluids Laboratories}

Six universities were found to list experiment topics from their thermal sciences and fluids laboratory courses online. Experiment topics listed from these universities are as follows: radiation, extended surface heat transfer, conduction, transient heat transfer, pipe flow losses, flows over various geometries, pressure measurement, temperature measurement, internal combustion engine analysis, refrigeration cycles, heat pump cycles, viscosity measurement, flowmeter calibration, heat exchanger, natural convection, forced convection, flame temperature, flow transition to turbulence, wake interference, airfoil stall, data acquisition, vacuum engineering, thermocouples, calorimetry and mass flow measurement devices. This is by no means a complete list of all topics currently covered in thermal sciences and fluids laboratory courses. Nor is it a complete list of experiments available at these universities. It is possible that the surveyed websites have not been updated recently and are incomplete. However, this list of topics shows that the experiments described in this thesis may involve underrepresented topics in courses of this type. Also included in this survey were two well known manufacturers of educational bench top experiments. It was found that these companies do not manufacture anything similar to either experiment discussed in this thesis. 


\section{Chapter 3 - Design of Systems}

Both systems were designed to demonstrate basic thermodynamic principles. The heat exchanger experiment has been designed to condense steam using a room temperature water spray. This system mixes high energy steam and relatively low energy water which demonstrates the small amount of steam that is needed to significantly change the temperature of the water spray. The enthalpy pipe experiment has been designed to demonstrate the method used in development of the thermodynamic property tables. The system demonstrates that an enthalpy generation can be calculated from a known heat input and mass flow rate. Appendix A contains a list of all parts used in each system.

\subsection{Heat Exchanger Design}

Figure 3.1 is a schematic of the heat exchanger system. Letters A, B and C located inside of squares mark entrance and exit streams. Steam enters the cyclone from the left and is controlled by a ball valve. The cyclone is intended to remove a significant portion of water in the wet steam available in the lab. The water drops accumulate in the bottom of the cyclone and can be emptied into the drain line when the drain valve, located below the cyclone, is opened. A cyclone separates particles or water drops from a flow by using the principle that, in order for a particle to be carried upward in a vertical flow, a sufficient drag force must be exerted on the particle. The drag force on a particle is proportional to the velocity of the flow in which it is contained. For a cyclone to be effective an outlet pipe 3 times the diameter of the inlet pipe is necessary. The steam line available in the laboratory is $3 / 4$ inch pipe. The inner diameter (ID) of $3 / 4$ inch pipe is slightly below $1 \mathrm{inch}$. It was convenient to use the $3 / 4$ inch pipe size as the inlet of the cyclone and 3 inch pipe, which has an ID slightly larger than 3 inches, for the outlet. 


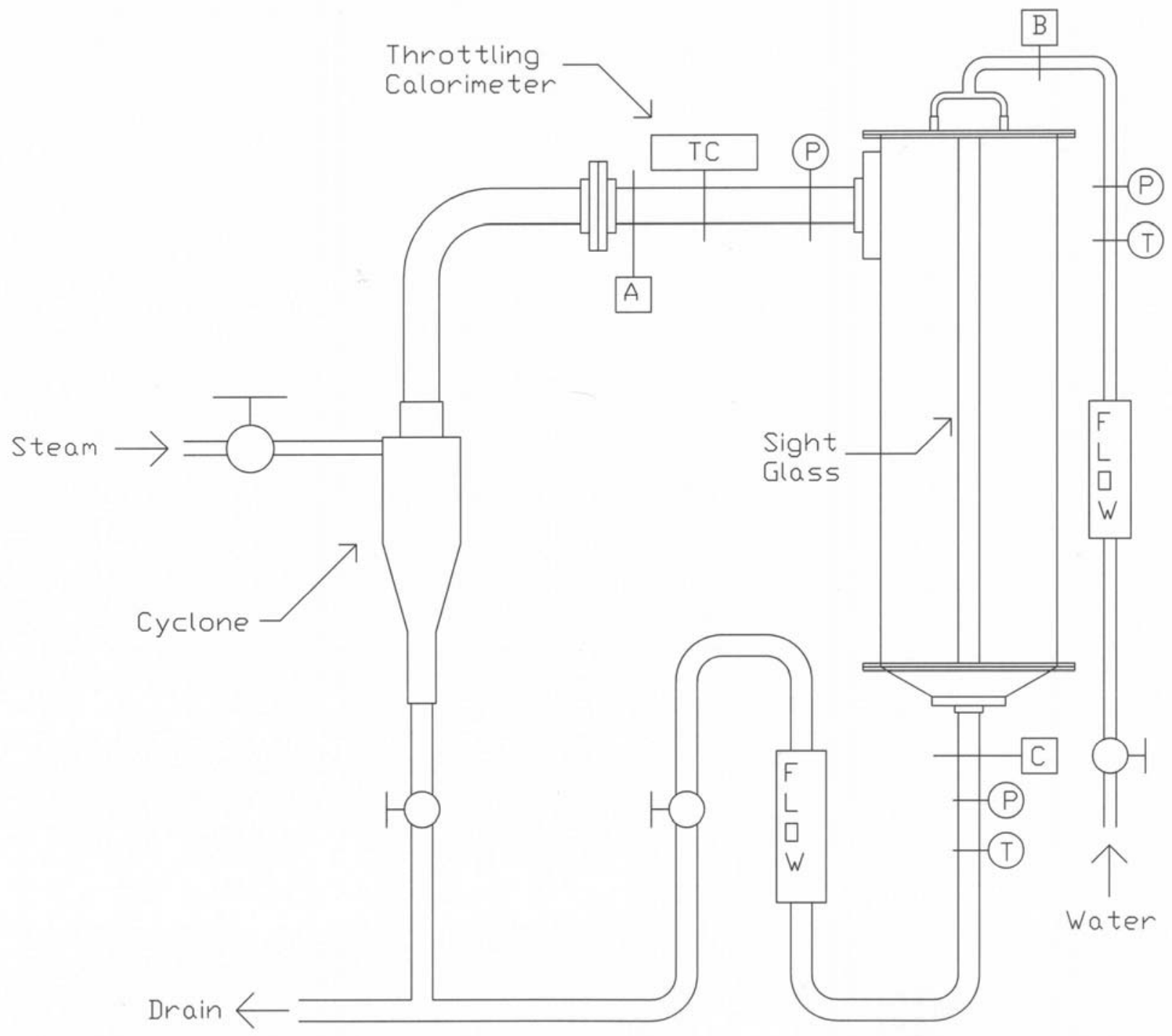

Figure 3.1 - Heat Exchanger System

Higher quality steam then exits the top of the cyclone through a pipe and enters the heat exchanger. At location A, a flange was necessary to accommodate the threaded fittings in the side of the heat exchanger and the top of the cyclone. The steam is condensed by a water spray that enters the heat exchanger from the location B. The water spray is controlled by a gate valve and is fed to the nozzles by a four-way flow splitter (only two nozzle inlets are shown). Water 
then exits the bottom of the chamber through a drain line, $\mathrm{C}$. The drain line passes through a second gate valve and into the drain.

The heat exchanger was designed to have a large amount of flexibility in operation due to the fact that the quality of the building steam was unknown and the unknown effectiveness of the water spray in condensing the steam. However, it was known that the maximum flowrate of water from a typical city water supply is approximately 5 gallons per minute. This provided a starting point for determination of system flowrates. In an industrial feedwater heater the condensation of steam adds approximately 20 percent to the mass flow rate of the water spray (Moran and Shapiro, 2000). The inlet water supply line is $1 / 2$ inch copper tubing. In order for the drain line to accommodate the additional flow of condensed steam 3/4 inch copper tubing was chosen. The size and shape of the heat exchanger itself was chosen to accommodate the

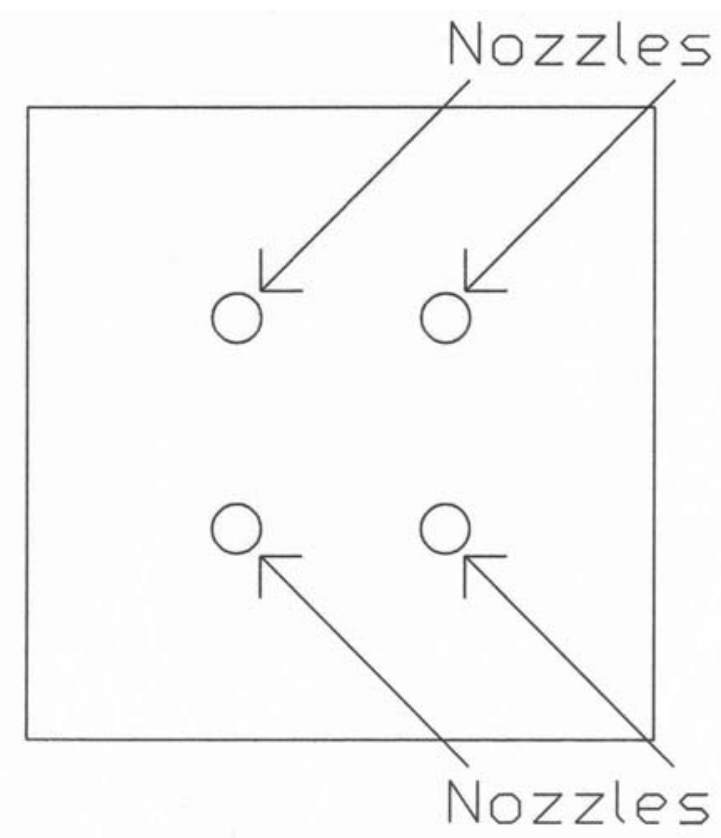

Figure 3.2 - Heat Exchanger Nozzle Arrangement 
symmetrical arrangement of four nozzles in the lid (Figure 3.2) and to give sufficient vertical distance for the water and steam droplets to interact before reaching the bottom of the chamber.

All of the instrumentation used in the system is shown schematically in figure 3.1.

Pressure gages are represented by a "P" inside of a circle, thermocouple positions are represented by a "T" inside of a circle and flowmeters positions are shown by a rectangle in the pipe with "FLOW" inside of it. Valves are represented by a circle in the pipe with a tee representing the valve handle. The rectangle with a "TC" inside of it represents the position of a throttling calorimeter. This instrument measures the enthalpy of the steam by extracting a small amount of steam from the line, expanding it to atmospheric pressure through an orifice and measuring the temperature of the expanded steam with a thermometer. This temperature is then used to determine the steam enthalpy. This is done by determining the enthalpy value of the expanded steam at the local atmospheric pressure. This value is equal to the enthalpy of the steam in the line because the expansion through the orifice is a constant enthalpy process.

\subsection{Enthalpy Pipe Design}

Figure 3.3 is a schematic of the enthalpy pipe system. Water enters the system on the left and is controlled by a gate valve. The middle section of the pipe is insulated and heated. The heated pipe length is $8 \mathrm{ft}$, however is not shown to scale. This section of the system is $1 / 4 \mathrm{inch}$ schedule 40 cast red brass pipe. The inside diameter (ID) is 0.364 inches and the outside diameter (OD) is 0.540 inches. The insulation is melamine foam pipe insulation with a thickness of 1 inch. The insulation manufacturer provides the following equation (3.1) for heat loss determination.

$$
\dot{Q}=0.26 \frac{A \Delta T}{75 t} \frac{B T U}{h r}
$$


Here, $A$ is the area $\left(\mathrm{ft}^{2}\right)$ of the insulation surface exposed to the surroundings, $\Delta T$ is the temperature difference $\left({ }^{\circ} \mathrm{F}\right)$ between the pipe wall and the surroundings and $t$ is the insulation thickness (in). Equation 3.1 was used to determine the heat loss through the insulation. The temperature of the pipe wall was estimated as an average value and the area used in the calculation was the outside area of the insulation. The water exits the system through a ball valve on the right side. The valve on the drain side provides a way to pressurize the system and assure that the pipe remains full during system operation.

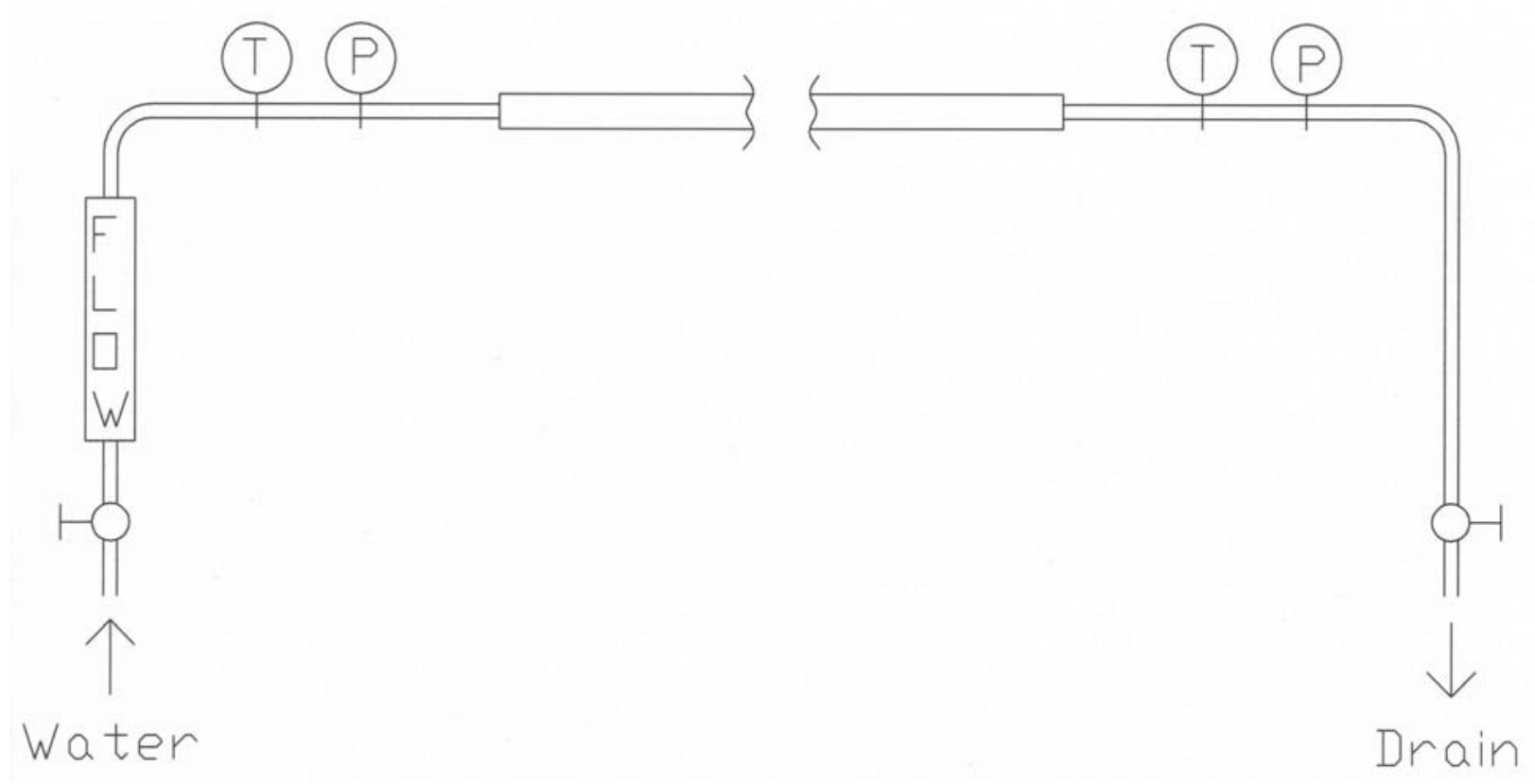

Figure 3.3 - Enthalpy Pipe System

In order to control the cost of the system a heating tape was chosen that could plug directly into the 120 volt power supply that was already available in the laboratory. This would alleviate the cost of a power supply system for heating elements. Due to the limitations of power available from a conventional wall outlet, the power supplied by the heating tape would be limited and this would determine the flow rates used in the experiment. 
The heating tape selected provides a maximum of 720 watts $(2457 \mathrm{BTU} / \mathrm{hr})$ from the 120 volt power source. The heating tape was wrapped around the pipe evenly to create a uniform heat input into the flow. A range for the experiment's enthalpy generation was chosen to be 15 to $150 \mathrm{BTU} / \mathrm{lb}$. Equation (1.21) was then used to calculate the mass flow rates required to satisfy the selected range. The necessary mass flow rates were determined to be 16.5 to $165 \mathrm{lb} / \mathrm{hr}$. This corresponds to a volume flow rate range of 1.96 to $19.6 \mathrm{gal} / \mathrm{hr}$. The Reynolds number ranges from 700 to 3700 . A flowmeter was then selected that provided the best combination of cost, accuracy and adherence to the desired volume flow rate range.

The selected flowmeter measures the volumetric water flowrate in cubic centimeters (cc) per minute. This flowmeter also has air calibration data that will allow for future use as an air enthalpy change experiment if so desired. The pressure and temperature are measured at both the entrance and exit of the insulated and heated portion of the pipe. The pressure is measured by commercial grade pressure gages from Omega Inc. The temperature is measured by $\mathrm{K}$ type thermocouples and digital thermocouple readers also from Omega Inc. The power output of the heating tape, $\dot{Q}_{\text {elec }}$, is calculated by measuring the resistance, $\Omega$, of the heating tape with a multimeter and measuring the voltage, $\varepsilon$, of the power outlet the tape is plugged into and then calculating power according to equation (3.2).

$$
\dot{Q}_{\text {elec }}=\frac{\varepsilon^{2}}{\Omega}
$$




\section{Chapter 4 - Calibration of Systems}

When analyzing a system it is extremely important to insure that the measurements taken are accurate and to know the degree of accuracy of the measurements. In these laboratory experiments it is nearly impossible to demonstrate important engineering concepts without accurate instrumentation. The instrumentation for the experiments was chosen with an emphasis on this principle as well as limiting cost.

\subsection{Heat Exchanger Calibration}

The instrumentation for the heat exchanger experiment consists of three pressure gages, two K-type thermocouples with digital readouts, two flowmeters and a throttling calorimeter. The pressure gages, flowmeters and throttling calorimeter are industrial models and have no adjustments for calibration. The digital readouts were set to the K-type thermocouples. This was accomplished by adjusting the settings of the readouts to read K-type and then establishing a set point in an ice bath which is exactly $32^{\circ} \mathrm{F}$. During this procedure the digital readouts adjust their programmed temperature-voltage curves to correspond with the known measurement of 32 ${ }^{\circ} \mathrm{F}$. As stated by the manufacturer, the thermocouples have an accuracy of plus or minus $3.96^{\circ} \mathrm{F}$. The pressure gages are tested by the manufacturer and guaranteed to be within $3 \%$ of the measurement taken. The flowmeters are also manufacturer tested and have a guaranteed accuracy of $3 \%$ of the full scale reading. The full scale reading is 5 gallons per minute (GPM), therefore the flowmeters are accurate to within $0.15 \mathrm{GPM}$. The accuracy limitation of the throttling calorimeter relates to the divisions on the thermometer that measures the expanded steam. These divisions allow the thermometer to be read to the nearest $1{ }^{\circ} \mathrm{F}$. This corresponds to an uncertainty of plus or minus $2^{\circ} \mathrm{F}$. 
This information can be used to perform uncertainty analysis on the system. This analysis will predict uncertainties in all measurements and provide useful information to improve the accuracy of the system. Assigning uncertainties to each of the measurands using ASME standards (Beckwith et al, 1995) results in Table 4.1

Table 4.1 - Uncertainty of Measurands

\begin{tabular}{|c|c|}
\hline Measurand & Uncertainty (+ or - ) \\
\hline Temperature & $0.7^{\circ} \mathrm{F}$ \\
\hline Pressure & $3 \%$ of reading \\
\hline Volume Flow Rate (Heat Exchanger) & $0.15 \mathrm{GPM}$ \\
\hline Throttling Calorimeter & $2^{\circ} \mathrm{F} \mathrm{or} 1 \mathrm{BTU} / \mathrm{lb}_{\mathrm{m}}$ \\
\hline Volume Flow Rate (Enthalpy Pipe) & $68 \mathrm{cc} / \mathrm{min}$ \\
\hline Resistance (from multimeter) & $0.2 \mathrm{ohms}$ \\
\hline Voltage (from multimeter) & $0.2 \mathrm{volts}$ \\
\hline
\end{tabular}

\subsection{Enthalpy Pipe Calibration}

The instrumentation for the enthalpy pipe experiment consists of two pressure gages, two K-type thermocouples with digital readouts, one flowmeter and one multimeter. The accuracy of the pressure and temperature measurements are the same as described previously in the heat exchanger section. The flowmeter used in this experiment is tested by the manufacturer and ensured to be accurate within $5 \%$ of the full scale reading. The full scale reading is 1368 cubic centimeters per minute (cc/min), therefore the flowmeter is accurate to within $68 \mathrm{cc} / \mathrm{min}$. A multimeter is used to measure the resistance of the heating tape and the voltage of the outlet it is plugged into during operation. The multimeter is able to measure resistance to the nearest 0.1 ohm and voltage to the nearest 0.1 volt. 


\section{Chapter 5 - Experiment Hand-out Sheets}

This chapter consists of documents that would be used in the laboratory course. These include an instruction hand-out and a data reduction hand-out for each experiment. The instruction hand-outs include a brief introduction to the experiment, a schematic, operating procedure, tables for recording data and a list of what is to be presented in the student's lab report. The data reduction hand-outs include equations for data reduction and tables that are to be presented in the student's lab report.

\subsection{Instruction Hand-out for Heat Exchanger Experiment}

\section{Introduction}

The transfer of thermal energy from one fluid to another or by mixing is very important in many engineering systems. Applications include the cooling of liquid by air in an automotive radiator and the heating of condensed water by injection of steam in an open feedwater heater for power plants to name a couple. This experiment is an example of the latter application. The primary objective of this experiment is to demonstrate the small amount of steam that is necessary to heat a water spray. Another important objective is the measurement of the amount of energy contained in the steam. This will be accomplished through direct and indirect measurements. The enthalpy of the steam will be determined indirectly through measurements of flowrates, temperatures and pressures of the water spray and the exit stream. The enthalpy of the steam will be determined directly through the use of a throttling calorimeter. The calorimeter takes a small sample of the steam and expands it to atmospheric pressure through an orifice. This expansion is a constant enthalpy process. The temperature of the expanded steam is then measured and the enthalpy is determined from the steam tables according to the measured temperature at the measured atmospheric pressure.

The apparatus for this experiment consists of a heat exchanger in which a water spray and steam are mixed and exit through a drain line. Flowmeters, pressure gages and thermocouples are located in the water spray line and drain line. The steam flows through a cyclone which ensures that a considerable portion of condensed liquid is removed from the flow before it reaches the throttling calorimeter. This is necessary because the calorimeter is not accurate if the quality of steam it is measuring is less than 0.95 . Recall that steam may be a two phase mixture and the quality of steam is the ratio of the mass of vapor present to the total mass of the mixture. The pressure gage on the steam line is necessary if it is desired to calculate the quality of the steam. The entire heat exchanger apparatus is shown in Figure 1. 


\section{$\underline{\text { Experimental Procedure }}$}

1. Record the local barometric pressure.

2. Turn off the drain line valve and turn on the water spray valve.

3. When the water level in the site glass reaches the desired level adjust the drain line valve so that the two flowrates are equal.

4. Turn on the steam line valve and open the valve on the drain line of the cyclone.

5. When all of the water is emptied from the steam line and cyclone close the cyclone drain valve.

6. Adjust the water spray flowrate to the desired setting and adjust the steam valve to equalize the steam line pressure between 2 to 4 psig (if pressure is increasing reduce steam flow, if pressure is decreasing or a vacuum occurs increase the steam flow).

7. Adjust the drain flowrate so that the site glass level remains constant (THIS IS CRITICAL).

8. Record the pressure, temperature and flowrate of the water spray.

9. Record the pressure, temperature and flowrate of the exit line.

10. Record the pressure and the calorimeter temperature of the steam line.

Use Table 1 on the next page to record the heat exchanger experiment data. 


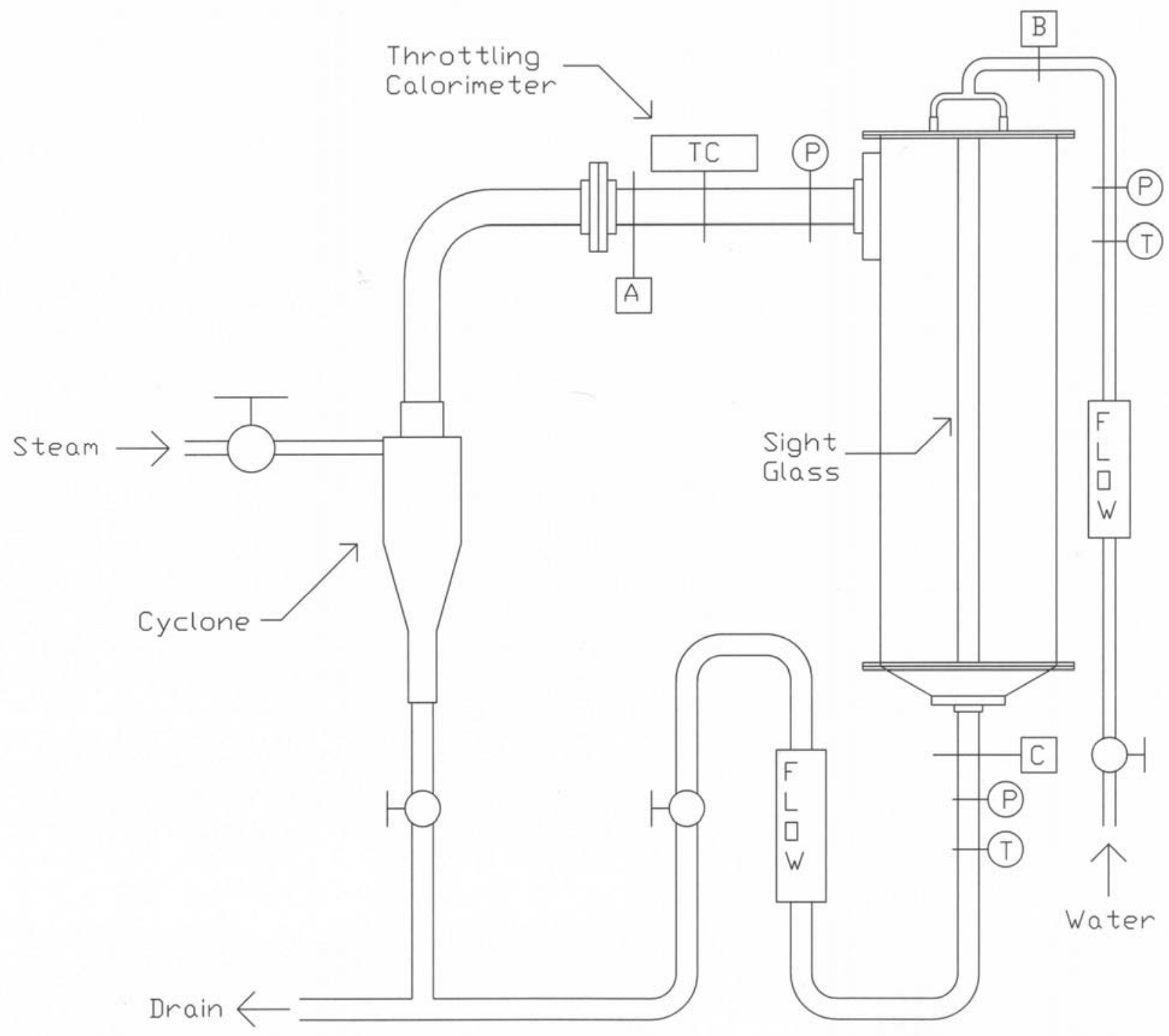

Figure 1 - Heat Exchanger Apparatus 
Table 1 - Heat Exchanger Experiment Data Record.

\begin{tabular}{|c|c|c|c|c|c|c|c|}
\hline $\begin{array}{c}\mathrm{T}_{1} \\
\left({ }^{\circ} \mathrm{F}\right)\end{array}$ & $\begin{array}{c}\mathrm{P}_{1} \\
(\mathrm{psig})\end{array}$ & $\begin{array}{c}\mathrm{Q}_{1} \\
(\mathrm{GPM})\end{array}$ & $\begin{array}{c}\mathrm{T}_{3} \\
\left({ }^{\circ} \mathrm{F}\right)\end{array}$ & $\begin{array}{c}\mathrm{P}_{3} \\
(\mathrm{psig})\end{array}$ & $\begin{array}{c}\mathrm{Q}_{3} \\
(\mathrm{GPM})\end{array}$ & $\begin{array}{c}\mathrm{T}_{\mathrm{TC}} \\
\left({ }^{\circ} \mathrm{F}\right)\end{array}$ & $\begin{array}{c}\mathrm{P}_{3} \\
(\mathrm{psig})\end{array}$ \\
\hline & & & & & & & \\
\hline & & & & & & & \\
\hline & & & & & & & \\
\hline & & & & & & & \\
\hline
\end{tabular}

\section{$\underline{\text { Report }}$}

1. Convert the recorded flow rates to mass flow rates and calculate the mass flow rate of steam.

2. Determine the enthalpy values for the water spray and exit streams and calculate the enthalpy of the steam.

Place parts 1 and 2 in the same table.

3. Determine the enthalpy of the steam from the throttling calorimeter readings.

4. Assuming the calorimeter enthalpy reading to be correct, calculate the percent error of the enthalpy calculation in part 2 .

Place parts 3 and 4 in a second table. 


\subsection{Data Reduction Hand-out for Heat Exchanger Experiment}

\section{$\underline{\text { THEORY }}$}

Complete each of the following tasks and record in TABLE 1.

1. Determine the density of the water spray according to $T_{1}$ and $P_{1}$.

2. Determine the density of the exit stream according to $T_{3}$ and $P_{3}$.

3. Convert the recorded volume flow rates to mass flow rates.

$\dot{V}\left(\frac{g a l}{\min }\right) \times 0.13368\left(\frac{f t^{3}}{g a l}\right) \times \rho\left(\frac{l b_{m}}{f t^{3}}\right)=\dot{m}\left(\frac{l b_{m}}{\min }\right)$

4. Calculate the mass flow rate of the steam.

$\dot{m}_{2}=\dot{m}_{3}-\dot{m}_{1}$

5. Determine the enthalpy values of the spray and exit streams from the steam tables.

6. Calculate the enthalpy of the steam.

$$
H_{2}=\frac{\dot{m}_{3} H_{3}-\dot{m}_{1} H_{1}}{\dot{m}_{2}}
$$

\section{EXPERIMENT}

Complete each of the following tasks and record in TABLE 2.

7. Determine the enthalpy values of the steam from the steam tables corresponding to the calorimeter temperature at atmospheric pressure.

8. Assuming the experimental value is correct, calculate the percent error. 
TABLE 1. Results of Steam Enthalpy from Theory

\begin{tabular}{|c|c|c|c|c|c|c|c|}
\hline $\begin{array}{l}\rho \text { Spray } \\
\left(\frac{l b_{m}}{f t^{3}}\right)\end{array}$ & $\begin{array}{l}\rho \text { Exit } \\
\left(\frac{l b_{m}}{f t^{3}}\right)\end{array}$ & $\begin{array}{l}\dot{m} \text { Spray } \\
\left(\frac{l b_{m}}{\min }\right)\end{array}$ & $\begin{array}{l}\dot{m} \text { Exit } \\
\left(\frac{l b_{m}}{\min }\right)\end{array}$ & $\begin{array}{c}\dot{m} \text { Steam } \\
\left(\frac{l b_{m}}{\min }\right)\end{array}$ & $\begin{array}{l}H \text { Spray } \\
\left(\frac{B T U}{l b_{m}}\right)\end{array}$ & $\begin{array}{c}H \text { Exit } \\
\left(\frac{B T U}{l b_{m}}\right)\end{array}$ & $\begin{array}{l}H \text { Steam } \\
\left(\frac{B T U}{l b_{m}}\right)\end{array}$ \\
\hline & & & & & & & \\
\hline & & & & & & & \\
\hline & & & & & & & \\
\hline & & & & & & & \\
\hline & & & & & & & \\
\hline
\end{tabular}

TABLE 2. Steam Enthalpy from Experiment and Percent Error

\begin{tabular}{|l|c|l|}
\hline $\begin{array}{c}\text { Steam Enthalpy from Theory } \\
\left(\frac{B T U}{l b_{m}}\right)\end{array}$ & $\begin{array}{c}\text { Steam Enthalpy form } \\
\text { Throttling Calorimeter } \\
\left(\frac{B T U}{l b_{m}}\right)\end{array}$ & \% Error \\
\hline & & \\
\hline & & \\
\hline & & \\
\hline & & \\
\hline
\end{tabular}




\subsection{Instruction Hand-out for Enthalpy Pipe Experiment}

\section{Introduction}

The thermodynamic property tables are very important in analyzing thermal systems. These tables exist for many common engineering fluids such as saturated water, steam, saturated steam, hydrogen, nitrogen, and man made substances commonly used in refrigeration cycles. This experiment demonstrates the process by which these property tables were constructed. The inlet and outlet temperatures and pressures of a heated pipe flow are recorded along with the water flowrate and the power consumed by the heating tape. The flowrate and power input are then used to calculate the enthalpy generated by the heating of the flow. The recorded temperatures and pressures are used to determine the actual enthalpy generation from existing thermodynamic tables.

The apparatus for this experiment consists of a heated and insulated pipe flow, pressure gages and thermocouples at each end of the heated/insulated section and a flowmeter. Water exits the system through a valve used to control the system pressure and into a drain line. The entire apparatus is shown in Figure 1.
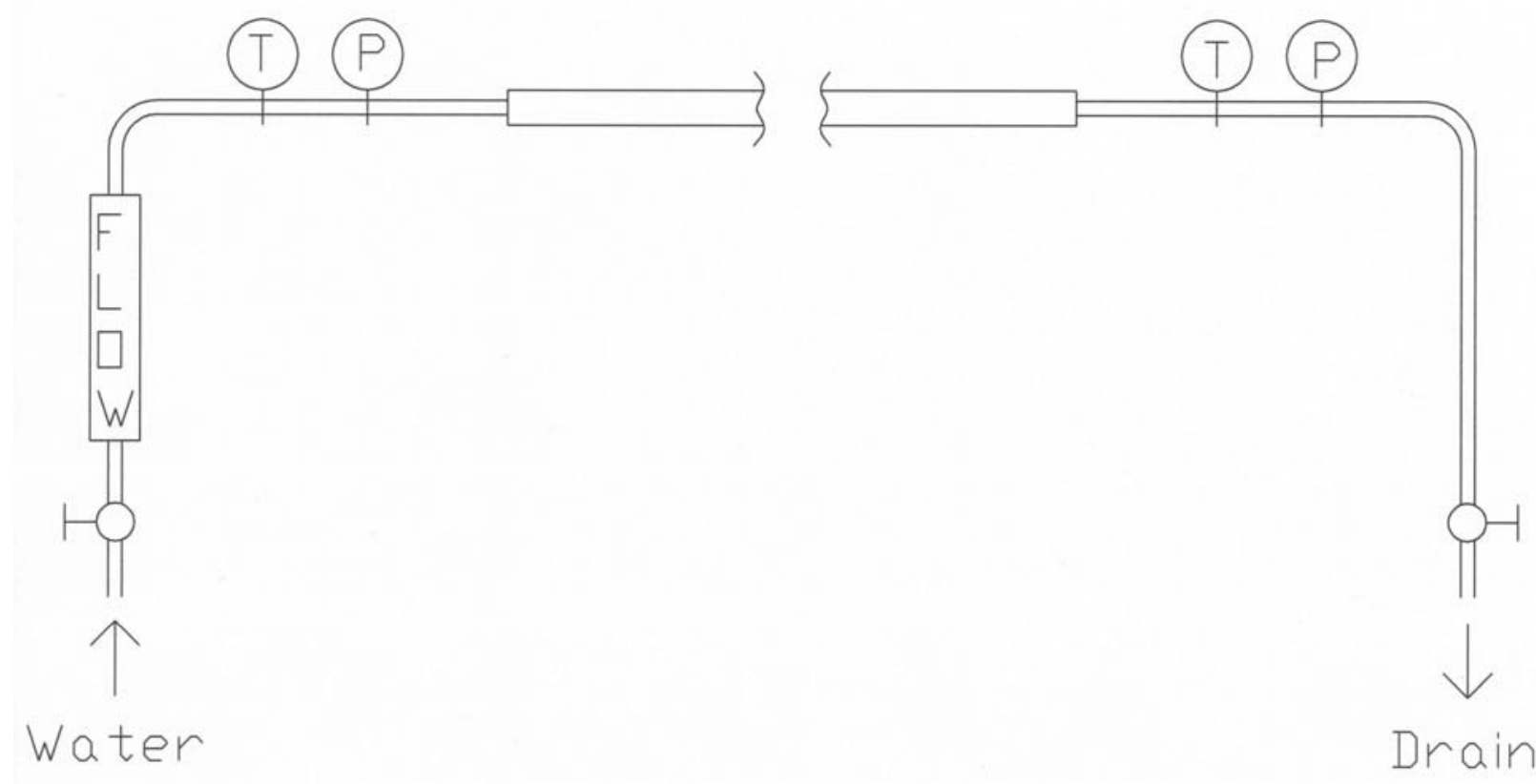

Figure 1 - Generation of Enthalpy Data Apparatus

\section{$\underline{\text { Experimental Procedure }}$}

1. Measure the local barometric pressure.

2. Measure the resistance of the heating tape with the adjustment set to $100 \%$.

3. Turn on the water valve and adjust the flowrate to the desired setting. 
4. Adjust the drain valve so that the pressure gages read 15 to $30 \mathrm{psig}$.

5. Plug in the heating tape and measure and record the voltage of the outlet.

6. Record the flowrate of the water flow.

7. Record the pressure and temperature at the inlet and outlet of the heated section.

Use TABLE 1 below to record the enthalpy generation experimental data.

TABLE 1 - Enthalpy Generation Experiment Data Record.

\begin{tabular}{|c|c|c|c|c|}
\hline $\begin{array}{c}\text { Flowrate } \\
(\mathrm{mm})\end{array}$ & $\begin{array}{c}\mathrm{T}_{1} \\
\left({ }^{\circ} \mathrm{F}\right)\end{array}$ & $\begin{array}{c}\mathrm{P}_{1} \\
(\mathrm{psig})\end{array}$ & $\begin{array}{c}\mathrm{T}_{2} \\
\left({ }^{\circ} \mathrm{F}\right)\end{array}$ & $\begin{array}{c}\mathrm{P}_{2} \\
(\mathrm{psig})\end{array}$ \\
\hline & & & & \\
\hline & & & & \\
\hline & & & & \\
\hline & & & & \\
\hline & & & & \\
\hline & & & & \\
\hline
\end{tabular}

\section{$\underline{\text { Report }}$}

1. Convert the recorded flow rates to mass flow rates.

2. Calculate the heat input from the heating tape.

3. Calculate the change in enthalpy from the heat input and mass flow rates.

Place parts 1, 2 and 3 in the same table.

4. Determine the enthalpy values at the entrance and exit of the heated pipe section from the temperature and pressure readings.

5. Calculate the change in enthalpy from part 4 .

6. Assuming part 3 to be correct, calculate the percent error of the change in enthalpy calculation in part 5 .

Place parts 4, 5, and 6 in a second table.

7. Plot change in enthalpy from parts 3 and 5 against mass flowrate on the same graph. 


\subsection{Data Reduction Hand-out for Enthalpy Pipe Experiment}

\section{$\underline{\text { THEORY }}$}

Complete each of the following tasks and record in TABLE 1.

1. Determine the Water Density in the Steam Tables according to $T_{1}$ and $P_{1}$.

2. Convert the recorded volume flow rates to mass flow rates.

$$
\dot{V}\left(\frac{\mathrm{cm}^{3}}{\min }\right) \times 0.061024\left(\frac{i n^{3}}{\mathrm{~cm}^{3}}\right) \times \frac{1}{1728}\left(\frac{f t^{3}}{i n^{3}}\right) \times \rho\left(\frac{l b_{m}}{f t^{3}}\right) \times 60\left(\frac{\mathrm{min}}{h r}\right)=\dot{m}\left(\frac{l b_{m}}{h r}\right)
$$

3. Convert the recorded current to heat input.

$$
\begin{aligned}
& \frac{(\text { Volts })^{2}}{\text { Ohms }}=\text { Watts }=\dot{Q}(\text { Watts }) \\
& \dot{Q}(\text { Watts }) \times 3.413\left(\frac{\text { Btu } / h r}{\text { Watts }}\right)=\dot{Q}\left(\frac{\text { Btu }}{h r}\right)
\end{aligned}
$$

4. Calculate change in enthalpy for each setting.

$$
\Delta H\left(\frac{B t u}{l b_{m}}\right)=\frac{\dot{Q}\left(\frac{B t u}{h r}\right)}{\dot{m}\left(\frac{l b_{m}}{h r}\right)}
$$

\section{EXPERIMENT}

Complete Each of the following tasks and record in TABLE 2.

5. Determine the enthalpy values for the pipe entrance and exit conditions from the Thermodynamic Tables.

6. Calculate the change in enthalpy between the pipe entrance and exit. 
TABLE 1. Results of Enthalpy Change for Heated Pipe Flow

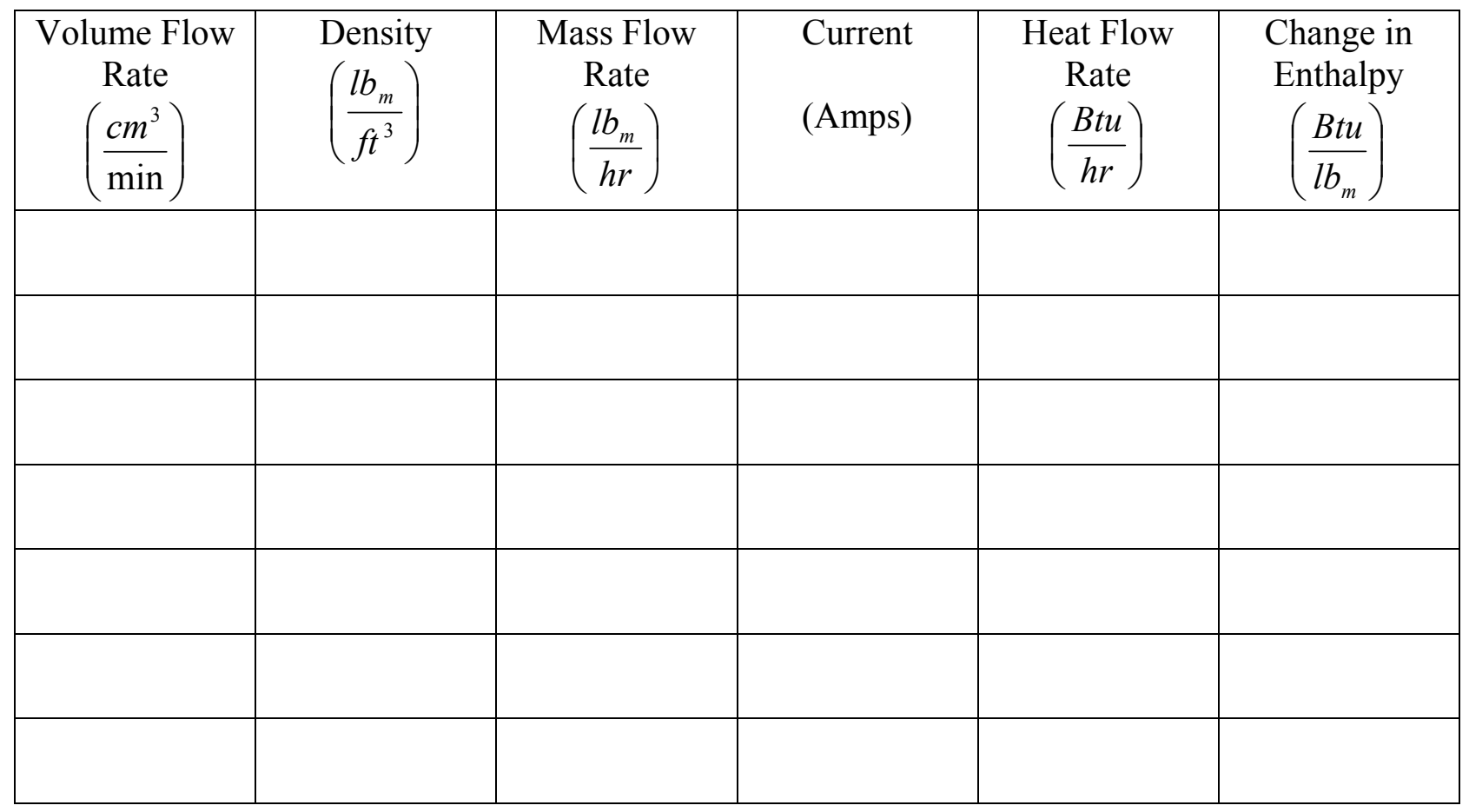

TABLE 2. Enthalpy Change from Thermodynamic Tables

\begin{tabular}{|l|l|l|l|l|l|l|l|}
\hline $\begin{array}{c}\text { Volume } \\
\text { Flow } \\
\text { Rate } \\
\left(\frac{\mathrm{cm}^{3}}{\mathrm{~min}}\right)\end{array}$ & $\mathrm{T}_{1}\left({ }^{\circ} \mathrm{F}\right)$ & $\mathrm{P}_{1}(\mathrm{psia})$ & $\mathrm{H}_{1}\left(\frac{B t u}{l b_{m}}\right)$ & $\mathrm{T}_{2}\left({ }^{\circ} \mathrm{F}\right)$ & $\mathrm{P}_{2}(\mathrm{psia})$ & $\mathrm{H}_{2}\left(\frac{B t u}{l b_{m}}\right)$ & $\begin{array}{c}\text { Change in } \\
\text { Enthalpy } \\
\left(\frac{B t u}{l b_{m}}\right)\end{array}$ \\
\hline & & & & & & & \\
\hline \\
\hline
\end{tabular}


7. Assuming the textbook property values are correct, calculate the percent error.

TABLE 3. Experimental and Textbook Values for Enthalpy Change Along the Heated Pipe

\begin{tabular}{|l|l|l|l|}
\hline $\begin{array}{c}\text { Volume Flow Rate } \\
\left(\frac{\mathrm{cm}^{3}}{\mathrm{~min}}\right)\end{array}$ & $\begin{array}{c}\text { Experimental Change } \\
\text { in Enthalpy } \\
\left(\frac{B t u}{l b_{m}}\right)\end{array}$ & $\begin{array}{c}\text { Textbook Change in } \\
\text { Enthalpy } \\
\left(\frac{B t u}{l b_{m}}\right)\end{array}$ & \% Error \\
\hline & & & \\
\hline & & & \\
\hline & & & \\
\hline & & & \\
\hline & & & \\
\hline
\end{tabular}




\section{Chapter 6 - Results}

The heat exchanger and enthalpy pipe experiments were run in accordance with the corresponding experimental procedure in the previous chapter. The raw data collected for each experiment is located in Appendix B. This data was reduced in accordance with the corresponding data reduction section in the previous chapter. All of the calculations were completed in a separate spreadsheet for each experiment. These spreadsheets are located in Appendix C. The following sections will include discussion of these results

\subsection{Heat Exchanger}

Table 6.1 shows the results of the theoretical portion of the experiment. The data discussed in this section was taken during runs in which the chamber was uninsulated. The data reduction handout in the previous section assumes that the heat loss from the chamber is neglibable, however when uninsulated this assumption is invalid. The heat loss was estimated using natural convection analysis described by Mills (1995) and included in the energy balance used to calculate the theoretical steam enthalpy. Calculations used to determine the heat loss are located in Appendix C. The chamber wall was assumed to be at the exit stream temperature and

Table 6.1 - Results of Steam Enthalpy from Theory

\begin{tabular}{|c|c|c|c|c|c|c|c|}
\hline $\begin{array}{c}\rho \text { Spray } \\
\left(\frac{l b_{m}}{f t^{3}}\right)\end{array}$ & $\begin{array}{c}\rho \text { Exit } \\
\left(\frac{l b_{m}}{f t^{3}}\right)\end{array}$ & $\begin{array}{c}\dot{m} \text { Spray } \\
\left(\frac{l b_{m}}{\min }\right)\end{array}$ & $\begin{array}{c}\dot{m} \text { Exit } \\
\left(\frac{l b_{m}}{\min }\right)\end{array}$ & $\begin{array}{c}\dot{m} \text { Steam } \\
\left(\frac{l b_{m}}{\min }\right)\end{array}$ & $\begin{array}{c}H \text { Spray } \\
\left(\frac{B T U}{l b_{m}}\right)\end{array}$ & $\begin{array}{c}H \text { Exit } \\
\left(\frac{B T U}{l b_{m}}\right)\end{array}$ & $\begin{array}{c}H \text { Steam } \\
\left(\frac{B T U}{l b_{m}}\right)\end{array}$ \\
\hline 62.23 & 60.75 & 29.12 & 30.86 & 1.74 & 47.19 & 139.47 & 1740.8 \\
\hline 62.27 & 60.76 & 14.15 & 17.06 & 2.91 & 45.49 & 139.37 & 0632.9 \\
\hline 62.27 & 60.54 & 11.65 & 12.95 & 1.29 & 45.59 & 149.19 & 1171.0 \\
\hline 62.25 & 60.95 & 31.62 & 33.41 & 1.78 & 44.79 & 129.16 & 1677.9 \\
\hline 62.25 & 61.00 & 25.38 & 26.09 & 0.71 & 45.09 & 126.96 & 3169.0 \\
\hline 62.25 & 60.83 & 20.80 & 21.96 & 1.14 & 45.19 & 136.47 & 1874.2 \\
\hline
\end{tabular}


the ambient temperature was measured and found to be $68^{\circ} \mathrm{F}$ for all runs. The spray density was determined from property data (Moran and Shapiro, 2000) using the pressure and temperature readings on the water spray line. The exit density was determined from property data (Moran and Shapiro, 2000) using the pressure and temperature readings on the exit line. The enthalpy of the spray and exit streams were determined from property tables (Moran and Shapiro, 2000) using temperature and pressure readings from the appropriate stream. Table 6.2 shows the steam enthalpy as determined from the throttling calorimeter reading and the percent error associated with the readings. The percent error was calculated using the value from theory as the correct

Table 6.2 - Theoretical and Experimental Steam Enthalpy and Percent Error

\begin{tabular}{|c|c|c|}
\hline $\begin{array}{c}\text { Steam Enthalpy from Theory } \\
\left(\frac{B T U}{l b_{m}}\right)\end{array}$ & $\begin{array}{c}\text { Steam Enthalpy form } \\
\text { Throttling Calorimeter } \\
\left(\frac{B T U}{l b_{m}}\right)\end{array}$ & \% Error \\
\hline 1680.2 & 1151.0 & $-31.5 \%$ \\
\hline 596.6 & 1151.0 & $92.9 \%$ \\
\hline 1081.6 & 111.0 & $6.4 \%$ \\
\hline 1624.7 & 1151.0 & $-29.2 \%$ \\
\hline 3039.2 & 1151.0 & $-61.8 \%$ \\
\hline 1785.2 & 1151.5 & $-35.3 \%$ \\
\hline
\end{tabular}

value. Throughout the experiment the steam enthalpy should remain nearly constant. However the calculated enthalpy is not constant and contains some large errors. To determine the cause of these errors, an uncertainty analysis was performed on all calculations leading up to the determination of the steam enthalpy.

An uncertainty value was assigned to each measurand in Chapter 4 . These values were used in uncertainty propagation analysis to determine the expected uncertainty of each 
calculation that was performed. A separate propagation calculation was performed for each equation discussed in the Data Reduction section in Chapter 5. Details of these calculations are located in Appendix D. The first values to be examined were the spray and exit densities. The uncertainty of the density value is dictated by the uncertainty of the temperature reading. As stated in Chapter 4, the uncertainty of the temperature reading is $3.96^{\circ} \mathrm{F}$. The uncertainty of the density was determined by calculating the density at the limit of the temperature uncertainty and comparing it to the density at the recorded value. The uncertainty of the density is the difference in the density at the limit and the density at the recorded temperature. The uncertainty of the density was determined to be $0.05 \mathrm{lb}_{\mathrm{m}} / \mathrm{ft}^{3}$. This value is much less than one percent of the actual density in all cases. The next calculation examined was the conversion of volume flow rates to mass flow rates at the spray inlet and system outlet. As stated in Chapter 4, the uncertainty of the volume flow rate readings are $0.15 \mathrm{GPM}$. The uncertainty of these conversions is affected by this uncertainty as well as the uncertainty of the density. The uncertainty of the spray inlet mass flow rate was found to be $1.25 \mathrm{lb} / \mathrm{min}$. This value corresponds to a range of $3.9 \%$ to $10.7 \%$ of the readings. The uncertainty of the outlet mass flow rate was found to be range from 1.21 to $1.22 \mathrm{lb}_{\mathrm{m}} / \mathrm{min}$. These values correspond to a range of $3.7 \%$ to $9.4 \%$ of the readings. The uncertainty of the steam mass flow rate depends on the uncertainty of both the inlet and outlet readings, and is also affected by the ability to establish a steady state condition using the sight glass. The uncertainty of the steam mass flow rate due to uncertainties in the spray and outlet flow rates must be calculated and added to an estimated uncertainty due to change of the sight glass level. It was estimated that a maximum level change in the sight glass of $1 / 8$ inch may have occurred over a time of 45 seconds during each reading. The corresponding change in mass was calculated and averaged over the 45 second time period to estimate the uncertainty due to 
unsteadiness. These uncertainty values ranged from 0.84 to $0.85 \mathrm{lb} / \mathrm{min}$. The resulting uncertainty of the steam mass flow rate was found to range from 2.58 to $2.60 \mathrm{lb} / \mathrm{min}$. These values correspond to a range of $89.1 \%$ to $363.7 \%$ of the calculated values for the steam mass flow rate. It is obvious that the uncertainty values of the steam mass flow rate calculations are large and will cause large errors in the results of the heat exchanger experiment. The uncertainty of the steam enthalpy was calculated and found to range from 535.94 to $11058.12 \mathrm{BTU} / \mathrm{lb}_{\mathrm{m}}$. These values correspond to a range of $89.1 \%$ to $363.7 \%$ of the calculated values. It is obvious that this system in its initial configuration has significant errors. These errors will be addressed in Chapter 7.

\section{2 - Enthalpy Pipe}

Table 6.3 shows the results of the theoretical portion of the experiment. The volume flow rate was linearly interpolated using the flowmeter reading and the flowmeter calibration data located in Appendix E. The fluid density was determined from property data (Moran and Shapiro, 2000)

Table 6.3 - Results of Enthalpy Change for Heated Pipe Flow

\begin{tabular}{|c|c|c|c|c|}
\hline $\begin{array}{c}\text { Volume Flow } \\
\text { Rate } \\
\left(\frac{\mathrm{cm}^{3}}{\mathrm{~min}}\right)\end{array}$ & $\begin{array}{c}\text { Density } \\
\left(\frac{l b_{m}}{f t^{3}}\right)\end{array}$ & $\begin{array}{c}\text { Mass Flow Rate } \\
\left(\frac{l b_{m}}{h r}\right)\end{array}$ & $\begin{array}{c}\text { Heat Flow Rate } \\
\left(\frac{B t u}{h r}\right)\end{array}$ & $\begin{array}{c}\text { Change in } \\
\text { Enthalpy } \\
\left(\frac{B t u}{l b_{m}}\right)\end{array}$ \\
\hline 1242 & 62.19 & 163.7 & 2347 & 14.34 \\
\hline 857 & 62.19 & 112.9 & 2347 & 20.78 \\
\hline 751 & 62.19 & 99.0 & 2347 & 23.72 \\
\hline 587 & 62.19 & 77.4 & 2347 & 30.34 \\
\hline 448 & 62.19 & 59.0 & 2347 & 39.76 \\
\hline 198 & 62.19 & 26.1 & 2347 & 89.96 \\
\hline 354 & 62.19 & 46.6 & 2347 & 50.32 \\
\hline
\end{tabular}


using the pressure and temperature at the entrance of the heated pipe section. The temperature at the pipe entrance varied $2^{\circ} \mathrm{F}$ and did not have a significant effect on the fluid density. The resistance of the heating tape and the voltage supplied by the outlet that the tape was plugged into were constant throughout the experiment; therefore the heat flow rate from the heating tape to the fluid was constant. The heat loss from the heating tape through the insulation and conduction along the pipe walls was estimated and found to be less than one percent of the heat generated by the tape. Table 6.4 shows the actual enthalpy change and the data required to determine the change. $\mathrm{T}_{1}$ and $\mathrm{P}_{1}$ correspond to the temperature and pressure readings at the entrance of the heated pipe section. $\mathrm{T}_{2}$ and $\mathrm{P}_{2}$ correspond to the temperature and pressure readings at the exit of the heated pipe section. $\mathrm{H}_{1}$ corresponds to the enthalpy of the fluid which is determined with the thermodynamic property tables (Moran and Shapiro, 2000) according to $\mathrm{T}_{1}$ and $\mathrm{P}_{1} \cdot \mathrm{H}_{2}$ corresponds to the specific enthalpy of the fluid according to $\mathrm{T}_{2}$ and $\mathrm{P}_{2}$. The change in specific enthalpy is calculated by subtracting $\mathrm{H}_{1}$ from $\mathrm{H}_{2}$.

Table 6.4 - Enthalpy Change from Thermodynamic Tables

\begin{tabular}{|c|c|c|c|c|c|c|c|}
\hline $\begin{array}{c}\text { Volume } \\
\text { Flow } \\
\text { Rate } \\
\left(\frac{c m^{3}}{\mathrm{~min}}\right)\end{array}$ & $\begin{array}{c}\mathrm{T}_{1} \\
\left({ }^{\circ} F\right)\end{array}$ & $\begin{array}{c}\mathrm{P}_{1} \\
(p s i a)\end{array}$ & $\begin{array}{c}\mathrm{H}_{1} \\
\left(\frac{B T U}{l b_{m}}\right)\end{array}$ & $\begin{array}{c}\mathrm{T}_{2} \\
\left({ }^{\circ} F\right)\end{array}$ & $\begin{array}{c}\mathrm{P}_{2} \\
(p s i a)\end{array}$ & $\begin{array}{c}\mathrm{H}_{2} \\
\left(\frac{B T U}{l b_{m}}\right)\end{array}$ & $\begin{array}{c}\text { Change in } \\
\text { Enthalpy } \\
\left(\frac{B t u}{l b_{m}}\right)\end{array}$ \\
\hline 1242 & 83.9 & 21.0 & 51.98 & 96.9 & 16.5 & 64.96 & 12.98 \\
\hline 857 & 83.6 & 25.5 & 51.68 & 102.2 & 22.0 & 70.24 & 18.56 \\
\hline 751 & 83.5 & 19.5 & 51.58 & 104.8 & 16.0 & 72.84 & 21.26 \\
\hline 587 & 83.3 & 28.0 & 51.38 & 109.0 & 24.0 & 77.02 & 25.64 \\
\hline 448 & 83.0 & 18.0 & 51.08 & 116.2 & 14.0 & 84.21 & 33.13 \\
\hline 198 & 81.8 & 24.0 & 49.88 & 153.4 & 20.0 & 121.36 & 71.48 \\
\hline 354 & 82.3 & 17.0 & 50.38 & 124.2 & 13.5 & 92.19 & 41.81 \\
\hline
\end{tabular}


Table 6.5 displays the final results of both calculations for enthalpy change. The percent error between the two was calculated. The percent error was calculated using the theoretical value as the correct value. As in with the heat exchanger, an uncertainty analysis was performed to determine the source of these errors. This was accomplished for each calculation leading up to the determination of the change in enthalpy of the experiment. Likewise, the details of the uncertainty analysis are located in Appendix D.

Table 6.5 - Theoretical and Experimental Values for Enthalpy Change and Percent Error

\begin{tabular}{|c|c|c|c|}
\hline $\begin{array}{c}\text { Volume Flow Rate } \\
\left(\frac{\mathrm{cm}^{3}}{\mathrm{~min}}\right)\end{array}$ & $\begin{array}{c}\text { Actual Change in } \\
\text { Enthalpy } \\
\left(\frac{B t u}{l b_{m}}\right)\end{array}$ & $\begin{array}{c}\text { Theoretical Change in } \\
\text { Enthalpy } \\
\left(\frac{B t u}{l b_{m}}\right)\end{array}$ & \% Error \\
\hline 1242 & 12.98 & 14.34 & $-9.5 \%$ \\
\hline 857 & 18.56 & 20.78 & $-10.7 \%$ \\
\hline 751 & 21.26 & 23.72 & $-10.4 \%$ \\
\hline 587 & 25.64 & 30.34 & $-15.5 \%$ \\
\hline 448 & 33.13 & 39.76 & $-16.7 \%$ \\
\hline 198 & 71.48 & 89.96 & $-20.5 \%$ \\
\hline 354 & 41.81 & 50.32 & $-16.9 \%$ \\
\hline
\end{tabular}

The uncertainty of the density in each reading was determined in the same manner as in the heat exchanger experiment. The uncertainty of the density was determined to be $0.05 \mathrm{lb}_{\mathrm{m}} / \mathrm{ft}^{3}$. The uncertainty of the flowmeter readings, as stated in Chapter 4, is $68 \mathrm{cc} / \mathrm{min}$. This value and the uncertainty of the density determine the uncertainty of the mass flow rate. The mass flow rate uncertainty was found to be $9.0 \mathrm{lb} / \mathrm{hr}$ for all readings. This corresponds to a range of $5.5 \%$ to $34.3 \%$ of the actual readings. As discussed previously, the heat input generated by the electric heating tape was determined indirectly by measuring the cold resistance of the tape and the voltage of the power source during operation. The uncertainty of this calculation is affected by 
the uncertainty involved with the reading from the multimeter that was used. However, the resistance of the heating tape during operation can change significantly from the cold measurement. Therefore, the uncertainty in the resistance measurement is significantly greater than the multimeter reading uncertainty. The change in resistance due to temperature can be calculated using the coefficient of resistance for the heating element material. The resistance can be accurately calculated if the operating temperature of the heating element is known. The heating tape used in this experiment is constructed of a proprietary material for which this data is not readily available. However, for a typical nichrome heating element operating at $600{ }^{\circ} \mathrm{C}$ the change in resistance is approximately $12 \%$. Taking this into account, an estimated value of $12 \%$ was assigned as the uncertainty of the resistance reading. This lead to an uncertainty of the heat input of $241 \mathrm{BTU} / \mathrm{hr}$, which corresponds to $10.3 \%$ of the actual calculated value. The uncertainty of the mass flow rate and heat input affect the uncertainty of the change in enthalpy. The change of enthalpy uncertainty was found to range from 1.67 to $32.25 \mathrm{BTU} / \mathrm{b}_{\mathrm{m}}$. This corresponds to a range of $11.6 \%$ to $35.8 \%$ of the actual calculated values. The uncertainty is lowest at the highest flowrate and steadily increases to a maximum at the lowest recorded flowrate. 


\section{Chapter 7 - Conclusions and Recommendations}

\subsection{Conclusions}

As stated in the objective, two experiments covering a number of fundamentals in thermodynamics, heat transfer and fluid mechanics were to be designed, constructed and operated. The results of operating both systems were discussed in Chapter 6. The heat exchanger experiment was operated without having any insulation installed. The heat loss of the uninsulated chamber was accounted for in the calculations. The loss was estimated using natural convection correlations (Mills, 1995) and the spreadsheets with these results are located in Appendix C. Insulation will be installed on the chamber prior to operation in the laboratory course. Therefore, the methods and equations discussed in previous chapters are valid for the course. The enthalpy pipe was analyzed taking all modes of heat loss into account (insulation and axial pipe wall conduction). The results of the loss estimations are located in Appendix C. The heat loss through the insulation and convection along the pipe wall was found to be less than one percent of the heat generated by the heating tape and is negligible.

\subsubsection{Heat Exchanger Experiment}

The errors reported in the typical lab report for the heat exchanger are high and inconsistent. It is likely that on two of the data points the system was not close enough to a steady state condition to yield consistent results. Three of the four remaining data points were extremely close to one another. Their average error is still high, $-35.8 \%$. Uncertainty analysis of the steam mass flow rate calculations reveals that the estimated measurement uncertainty is on the order of the observed error in the results. This reveals that the inability to determine the steam mass flow rate with sufficient accuracy is the dominant cause of the errors in the experiment. All other uncertainties are negligible when combined with the steam mass flow rate 
uncertainty. Therefore, these uncertainties must be addressed before the heat exchanger can be operated in the laboratory course.

\subsubsection{Enthalpy Pipe Experiment}

As in the Heat exchanger experiment, an uncertainty analysis was performed on all calculations and measurements. Again, the dominant error was found to originate in the uncertainty of the mass flow rate calculation. It is again obvious that the inability to accurately determine the mass flow rate is the primary reason for the error in the system. As in the heat exchanger, the uncertainties in the mass flow rate calculation must be addressed before the experiment can be used in the laboratory course.

\subsection{Recommendations for the Future}

Both systems were run initially without pressure regulators on the tap water lines. Some small fluctuations in water line pressure were observed and on occasion this made it necessary to repeat runs. It is recommended that pressure regulators be installed on all water supply lines in both systems.

\subsubsection{Heat Exchanger Experiment}

Several changes have already been implemented since the initial data was obtained. The heat exchanger has been redesigned to withstand a greater pressure and form a more suitable weld thickness. In the past, a siphoning effect in the drain line was preventing the chamber from maintaining a sufficient water level to prevent bubbles from being entrained in the exit flow. The drain valve was then added. This allowed any water level desired to be maintained in the chamber, but it also allowed pressure to build in the chamber. The pressure increases in the chamber if there in not sufficient water spray to condense the steam. A blow-off valve was installed on the chamber so that the chamber pressure does not exceed 5 psig. During initial 
operation the chamber pressure reached 8 psig and significant leaks developed in the chamber welds. The initial chamber was constructed from $1 / 8$ inch aluminum sheeting. It has been rebuilt from 1/4 inch aluminum sheeting with cross-bracing in the vertical center.

It is now recommended that the following additional alterations be performed to minimize the errors. The most significant reduction would result from the installation of more accurate flowmeters. The accuracy of the flow settings can be improved by replacing the gate valves in the experiment with globe valves. These valves will increase repeatability and experience less wear. The sight glass on the initial system does not have graduations. The steady state uncertainty can be reduced by the installation of an angled sight glass with closely spaced graduations. This will ensure a steady state water level in the chamber. Uncertainty analysis was performed on a new design with more accurate flowmeters and an angled sight glass. This analysis revealed that if flowmeters with an accuracy of $0.5 \%$ of the reading and a 30 degree angled sight glass with 1/16 inch marks were installed the uncertainty of the steam enthalpy calculation can be reduced to $15 \%$ of the calculated value. An example of a flowmeter with $0.5 \%$ accuracy would be Omega Engineering model FTB-402A which has a cost of $\$ 1148$ each.

The heat loss corrections were determined from natural convection analysis (Mills, 1995). Analysis of this type has an estimated uncertainty of $25 \%$. This uncertainty was insignificant in the analysis of the initial system due to large steam mass flow rate uncertainties. However, in a modified system these uncertainties become significant. It is recommended that insulation be installed on the chamber, cyclone and throttling calorimeter. This is necessary because the assumption of negligible heat loss from a well insulated system carries an uncertainty that is far less than the $25 \%$ uncertainty associated with the heat loss estimations. 


\subsubsection{Enthalpy Pipe Experiment}

No modifications have been made since the initial data was obtained. However, it is recommended that, in order to minimize errors in the enthalpy pipe experiment, a more accurate flowmeter be installed; and the use of an ammeter to measure the heating tape current during operation. Uncertainty analysis was performed on a new design with a more accurate flowmeter and ampmeter. This analysis revealed that if a flowmeter with an accuracy of $2 \%$ of the reading was installed the uncertainty of the change in enthalpy calculation can be reduced to $2.1 \%$ of the calculated value. An example of a flowmeter with this accuracy would be Omega Engineering model FL-115 which has a cost of \$268. 


\section{References}

Beckwith, Thomas G., et al. Mechanical Measurements. 5th ed. Reading, MA: AddisonWesley, 1995.

Edwards, C. Henry, and David E. Penney. Calculus with Analytical Geometry. 5th ed. Upper Saddle River, NJ: Prentice Hall, 1998.

Kline, S.J. "The Purposes of Uncertainty Analysis.” Journal of Fluids Engineering 105 (1985): 153-160.

Mills, Anthony F. Basic Heat and Mass Transfer. Chicago: Irwin, 1995.

Moffat, R.J. "Using Uncertainty Analysis in the Planning of an Experiment." Journal of Fluids Engineering 105 (1985): 173-78.

Moran, Michael J., and Howard N. Shapiro. Fundamentals of Engineering Thermodynamics.

4th ed. New York: Wiley, 2000.

White, Frank M. Fluid Mechanics. 4th ed. Boston: McGraw Hill, 1999.

White, Frank M. Viscous Fluid Flow. 2nd ed. Boston: McGraw Hill, 1991. 


\section{Appendix A - List of Parts}

\section{Heat Exchanger}

$1-12$ "x12"x36" insulated mixing chamber

$1-1$ " ID to 3" ID cyclone

2 - Omega FL-75A rotameters

2 - Omega KMQSS-125G-6 K-type thermocouples

2 - Omega DPI32 digital readouts

3 - Omega PGC-25L-15 pressure gages

1 - Croll-Reynolds steam calorimeter

4 - Spraying Systems 1/8 HH-5 nozzles

$1-1 / 2$ inch tubing gate valve

$2-3 / 4$ inch tubing gate valves

Various lengths of $1 / 2$ inch and $3 / 4$ inch copper tubing and fittings

Various lengths of $3 / 4$ inch black iron pipe and fittings

Various lengths of 3 inch black iron pipe and fittings

\section{Enthalpy Pipe}

$2-1 / 4$ inch $x$ 4' schedule 40 brass pipe sections

1 - Omega FL-1478-S rotameter

1 - Omega HTWC101-010 heating tape with controller

2 - Omega KMQSS-125G-6 K-type thermocouples

2 - Omega DPI32 digital readouts

2 - Omega PGC-25L-30 pressure gages

$2-1 / 2$ inch tubing ball valves

$2-2$ " $x$ 4' melamine foam insulation wraps

Various lengths of $1 / 2$ inch copper tubing and fittings 


\section{Appendix B - Raw Data}

\section{$\underline{\text { Heat Exchanger }}$}

\begin{tabular}{|c|c|c|c|c|c|c|c|}
\hline $\begin{array}{c}\mathrm{T}_{1} \\
\left({ }^{\circ} \mathrm{F}\right)\end{array}$ & $\begin{array}{c}\mathrm{P}_{1} \\
(\mathrm{psig})\end{array}$ & $\begin{array}{c}\mathrm{Q}_{1} \\
(\mathrm{GPM})\end{array}$ & $\begin{array}{c}\mathrm{T}_{3} \\
\left({ }^{\circ} \mathrm{F}\right)\end{array}$ & $\begin{array}{c}\mathrm{P}_{3} \\
(\mathrm{psig})\end{array}$ & $\begin{array}{c}\mathrm{Q}_{3} \\
(\mathrm{GPM})\end{array}$ & $\begin{array}{c}\mathrm{T}_{\mathrm{TC}} \\
\left({ }^{\circ} \mathrm{F}\right)\end{array}$ & $\begin{array}{c}\mathrm{P}_{2} \\
(\mathrm{psig})\end{array}$ \\
\hline 79.1 & $>15$ & 3.50 & 171.5 & 3.50 & 3.80 & 213 & 2.25 \\
\hline 77.4 & 2 & 1.70 & 171.4 & 2.00 & 2.10 & 213 & 1.00 \\
\hline 77.5 & $<0$ & 1.40 & 181.2 & 2.25 & 1.60 & 213 & 1.50 \\
\hline 76.7 & $>15$ & 3.80 & 161.2 & 2.50 & 4.10 & 213 & 1.75 \\
\hline 77.0 & $>15$ & 3.05 & 159.0 & 2.75 & 3.20 & 213 & 1.90 \\
\hline 77.1 & 13.75 & 2.50 & 168.5 & 3.80 & 2.70 & 214 & 3.00 \\
\hline
\end{tabular}

\section{Enthalpy Pipe}

\begin{tabular}{|c|c|c|c|c|}
\hline $\begin{array}{c}\text { Flowmeter } \\
(\mathrm{mm})\end{array}$ & $\begin{array}{c}\mathrm{T}_{1} \\
\left({ }^{\circ} \mathrm{F}\right)\end{array}$ & $\begin{array}{c}\mathrm{P}_{1} \\
(\mathrm{psig})\end{array}$ & $\begin{array}{c}\mathrm{T}_{2} \\
\left({ }^{\circ} \mathrm{F}\right)\end{array}$ & $\begin{array}{c}\mathrm{P}_{2} \\
(\mathrm{psig})\end{array}$ \\
\hline 140 & 83.9 & 21.0 & 96.9 & 16.5 \\
\hline 104 & 83.6 & 25.5 & 102.2 & 22.0 \\
\hline 93 & 83.5 & 19.5 & 104.8 & 16.0 \\
\hline 76 & 83.3 & 28.0 & 109.0 & 24.0 \\
\hline 60 & 83.0 & 18.0 & 116.2 & 14.0 \\
\hline 30 & 81.8 & 24.0 & 153.4 & 20.0 \\
\hline 50 & 82.3 & 17.0 & 124.2 & 13.5 \\
\hline
\end{tabular}




\section{Appendix C - Calculation Spreadsheets}

\section{Heat Exchanger - Initial Design}

The table below contains calculation data involving estimation of the heat loss and the mass change due to uncertainty. Del y is the estimated change in sight glass level in inches. Del t is the estimated time that elapses during the level change in seconds. Del V is the volume change associated with the level change. Del $\mathrm{m}$ is the mass change associated with the volume change in $1 b_{\mathrm{m}}$. Q dot is the estimated heat loss in BTU/min. U mdot is the steam mass flow rate uncertainty in $1 \mathrm{~b}_{\mathrm{m}} / \mathrm{min}$. U Qdot is the uncertainty associated with the heat loss.

\begin{tabular}{|c|c|c|}
\cline { 1 - 2 } $\begin{array}{c}\text { del y } \\
\text { (in) }\end{array}$ & 0.125 & \multicolumn{1}{|}{} \\
\cline { 1 - 2 } $\begin{array}{c}\text { del t } \\
\text { (s) }\end{array}$ & 45 & \\
\hline del V & del $\mathbf{~}$ & Q dot \\
\hline 0.0104 & 0.633 & 105.6 \\
\hline 0.0104 & 0.633 & 105.5 \\
\hline 0.0104 & 0.631 & 115.7 \\
\hline 0.0104 & 0.635 & 94.9 \\
\hline 0.0104 & 0.635 & 92.6 \\
\hline 0.0104 & 0.634 & 102.5 \\
\hline
\end{tabular}

\begin{tabular}{|c|c|}
\hline u mdot & u Qdot \\
\hline 0.844 & 26.4 \\
\hline 0.844 & 26.4 \\
\hline 0.841 & 28.9 \\
\hline 0.847 & 23.7 \\
\hline 0.847 & 23.2 \\
\hline 0.845 & 25.6 \\
\hline
\end{tabular}

The table on the following page contains calculation data involving the results and uncertainty analysis. The table is split into four levels and the numbering of terms corresponds to the locations in figure 2.1. The upper level contains raw data from the instrumentation discussed in chapter 4 . The second level contains calculations and conversions performed on the raw data. MFR columns contain mass flow rate calculations. $\rho$ columns contain density information. $\mathrm{H}$ columns contain specific enthalpy information. The third level contains uncertainty calculations of the values directly above in the second level. The fourth level contains uncertainty as a percentage of the values in the second level. 


\begin{tabular}{|c|c|c|c|c|c|c|c|c|}
\hline & Flow 1 (GPM) & T1 (F) & P1 (psig) & Flow 3 (GPM) & T3 (F) & P3 (psig) & T2 (F) & P2 (psig) \\
\hline $\mathbf{1}$ & 3.50 & 79.1 & $>15$ & 3.80 & 171.5 & 3.50 & 213 & 2.25 \\
\hline $\mathbf{2}$ & 1.70 & 77.4 & 2 & 2.10 & 171.4 & 2.00 & 213 & 1.00 \\
\hline $\mathbf{3}$ & 1.40 & 77.5 & $<0$ & 1.60 & 181.2 & 2.25 & 213 & 1.50 \\
\hline $\mathbf{4}$ & 3.80 & 76.7 & $>15$ & 4.10 & 161.2 & 2.50 & 213 & 1.75 \\
\hline $\mathbf{5}$ & 3.05 & 77.0 & $>15$ & 3.20 & 159.0 & 2.75 & 213 & 1.90 \\
\hline $\mathbf{6}$ & 2.50 & 77.1 & 13.75 & 2.70 & 168.5 & 3.80 & 214 & 3.00 \\
\hline
\end{tabular}

\begin{tabular}{|c|c|c|c|c|c|c|c|c|}
\hline & MFR 1 (Ib/min) & p1 (Ib/cu ft) & H1 (BTU/lb) & MFR 3 (Ib/min) & p3 & H3 & MFR 2 & H2 \\
\hline $\mathbf{1}$ & 29.12 & 62.23 & 47.19 & 30.86 & 60.75 & 139.47 & 1.74 & 1740.77 \\
\hline $\mathbf{2}$ & 14.15 & 62.27 & 45.49 & 17.06 & 60.76 & 139.37 & 2.91 & 632.87 \\
\hline $\mathbf{3}$ & 11.65 & 62.27 & 45.59 & 12.95 & 60.54 & 149.19 & 1.29 & 1170.99 \\
\hline $\mathbf{4}$ & 31.62 & 62.25 & 44.79 & 33.41 & 60.95 & 129.16 & 1.78 & 1677.88 \\
\hline $\mathbf{5}$ & 25.38 & 62.25 & 45.09 & 26.09 & 61.00 & 126.96 & 0.71 & 3168.97 \\
\hline $\mathbf{6}$ & 20.80 & 62.25 & 45.19 & 21.96 & 60.83 & 136.47 & 1.15 & 1874.19 \\
\hline
\end{tabular}

\begin{tabular}{|l|c|}
\hline & u MFR 1 \\
\hline $\mathbf{1}$ & 1.25 \\
\hline $\mathbf{2}$ & 1.25 \\
\hline $\mathbf{3}$ & 1.25 \\
\hline $\mathbf{4}$ & 1.25 \\
\hline $\mathbf{5}$ & 1.25 \\
\hline $\mathbf{6}$ & 1.25 \\
\hline
\end{tabular}

\begin{tabular}{|c|c|}
\hline & u MFR 1 I MFR 1 \% \\
\hline $\mathbf{1}$ & $4.3 \%$ \\
\hline $\mathbf{2}$ & $8.8 \%$ \\
\hline 3 & $10.7 \%$ \\
\hline $\mathbf{4}$ & $3.9 \%$ \\
\hline $\mathbf{5}$ & $4.9 \%$ \\
\hline $\mathbf{6}$ & $6.0 \%$ \\
\hline
\end{tabular}

\begin{tabular}{|c|c|}
\hline $\mathbf{~ u ~ H 1}$ & u MFR 3 \\
\hline 4.0 & 1.22 \\
\hline 4.0 & 1.22 \\
\hline 4.0 & 1.21 \\
\hline 4.0 & 1.22 \\
\hline 4.0 & 1.22 \\
\hline 4.0 & 1.22 \\
\hline
\end{tabular}

\begin{tabular}{|c|c|}
\hline u H1 / H1 \% & u MFR 3 / MFR 3 \% \\
\hline $8.5 \%$ & $3.9 \%$ \\
\hline $8.8 \%$ & $7.1 \%$ \\
\hline $8.8 \%$ & $9.4 \%$ \\
\hline $8.9 \%$ & $3.7 \%$ \\
\hline $8.9 \%$ & $4.7 \%$ \\
\hline $8.9 \%$ & $5.6 \%$ \\
\hline
\end{tabular}

\begin{tabular}{|c|c|c|}
\hline u H3 & u MFR 2 & u H2 \\
\hline 4.0 & 2.59 & 2497.57 \\
\hline 4.0 & 2.59 & 535.94 \\
\hline 4.0 & 2.58 & 2162.95 \\
\hline 4.0 & 2.59 & 2366.43 \\
\hline 4.0 & 2.60 & 11058.12 \\
\hline 4.0 & 2.59 & 4019.13 \\
\hline
\end{tabular}

\begin{tabular}{|c|c|c|}
\hline u H3 I H3 \% & u MFR 2 I MFR 2 \% & u H2 I H2 \% \\
\hline $2.9 \%$ & $148.4 \%$ & $143.5 \%$ \\
\hline $2.9 \%$ & $89.1 \%$ & $84.7 \%$ \\
\hline $2.7 \%$ & $199.4 \%$ & $184.7 \%$ \\
\hline $3.1 \%$ & $145.4 \%$ & $141.0 \%$ \\
\hline $3.2 \%$ & $363.7 \%$ & $348.9 \%$ \\
\hline $2.9 \%$ & $224.9 \%$ & $214.4 \%$ \\
\hline
\end{tabular}




\section{Heat Exchanger - Future Design}

The "Future Design" tables contain the same format as the "Initial Design" tables. The differences are contained in the uncertainty values. The steadiness uncertainty includes a inclined sight glass and a longer time period of observation. There is no heat loss estimation because the system is insulated and the assumption of no heat loss has an insignificant amount of uncertainty.

\begin{tabular}{|c|c|}
\hline $\begin{array}{c}\text { del } \mathbf{y} \\
\text { (in) }\end{array}$ & 0.0625 \\
\hline del t $\mathbf{~ ( s ) ~}$ & 300 \\
\hline del $\mathbf{~}$ & del $\mathbf{~}$ \\
\hline 0.0026 & 0.158 \\
\hline 0.0026 & 0.158 \\
\hline 0.0026 & 0.158 \\
\hline 0.0026 & 0.159 \\
\hline 0.0026 & 0.159 \\
\hline 0.0026 & 0.158 \\
\hline
\end{tabular}

\begin{tabular}{|c|}
\hline u mdot \\
\hline 0.032 \\
\hline 0.032 \\
\hline 0.032 \\
\hline 0.032 \\
\hline 0.032 \\
\hline 0.032 \\
\hline
\end{tabular}




\begin{tabular}{|c|c|c|c|c|c|c|c|c|}
\hline & Flow 1 (GPM) & T1 (F) & P1 (psig) & Flow 3 (GPM) & T3 (F) & P3 (psig) & T2 (F) & P2 (psig) \\
\hline $\mathbf{1}$ & 3.50 & 79.1 & $>15$ & 3.80 & 171.5 & 3.50 & 213 & 2.25 \\
\hline $\mathbf{2}$ & 1.70 & 77.4 & 2 & 2.10 & 171.4 & 2.00 & 213 & 1.00 \\
\hline $\mathbf{3}$ & 1.40 & 77.5 & $<0$ & 1.60 & 181.2 & 2.25 & 213 & 1.50 \\
\hline $\mathbf{4}$ & 3.80 & 76.7 & $>15$ & 4.10 & 161.2 & 2.50 & 213 & 1.75 \\
\hline $\mathbf{5}$ & 3.05 & 77.0 & $>15$ & 3.20 & 159.0 & 2.75 & 213 & 1.90 \\
\hline $\mathbf{6}$ & 2.50 & 77.1 & 13.75 & 2.70 & 168.5 & 3.80 & 214 & 3.00 \\
\hline
\end{tabular}

\begin{tabular}{|c|c|c|c|c|c|c|c|c|}
\hline & MFR 1 (lb/min) & p1 (lb/cu ft) & H1 (BTU/lb) & MFR 3 (lb/min) & p3 & H3 & MFR 2 & H2 \\
\hline $\mathbf{1}$ & 29.12 & 62.23 & 47.19 & 30.86 & 60.75 & 139.47 & 1.74 & 1680.22 \\
\hline $\mathbf{2}$ & 14.15 & 62.27 & 45.49 & 17.06 & 60.76 & 139.37 & 2.91 & 596.56 \\
\hline $\mathbf{3}$ & 11.65 & 62.27 & 45.59 & 12.95 & 60.54 & 149.19 & 1.29 & 1081.63 \\
\hline $\mathbf{4}$ & 31.62 & 62.25 & 44.79 & 33.41 & 60.95 & 129.16 & 1.78 & 1624.68 \\
\hline $\mathbf{5}$ & 25.38 & 62.25 & 45.09 & 26.09 & 61.00 & 126.96 & 0.71 & 3039.19 \\
\hline $\mathbf{6}$ & 20.80 & 62.25 & 45.19 & 21.96 & 60.83 & 136.47 & 1.15 & 1785.20 \\
\hline
\end{tabular}

\begin{tabular}{|c|c|}
\hline & U MFR 1 \\
\hline $\mathbf{1}$ & 0.15 \\
\hline $\mathbf{2}$ & 0.07 \\
\hline 3 & 0.06 \\
\hline $\mathbf{4}$ & 0.16 \\
\hline $\mathbf{5}$ & 0.13 \\
\hline 6 & 0.11 \\
\hline
\end{tabular}

\begin{tabular}{|c|c|}
\hline & U MFR 1 I MFR 1 \% \\
\hline $\mathbf{1}$ & $0.5 \%$ \\
\hline $\mathbf{2}$ & $0.5 \%$ \\
\hline 3 & $0.5 \%$ \\
\hline $\mathbf{4}$ & $0.5 \%$ \\
\hline $\mathbf{5}$ & $0.5 \%$ \\
\hline $\mathbf{6}$ & $0.5 \%$ \\
\hline
\end{tabular}

\begin{tabular}{|c|c|}
\hline $\mathbf{u ~ H 1}$ & $\mathbf{u ~ M F R ~ 3}$ \\
\hline 4.0 & 0.16 \\
\hline 4.0 & 0.09 \\
\hline 4.0 & 0.07 \\
\hline 4.0 & 0.17 \\
\hline 4.0 & 0.13 \\
\hline 4.0 & 0.11 \\
\hline
\end{tabular}

\begin{tabular}{|c|c|}
\hline u H1 / H1 \% & u MFR 3 / MFR 3 \% \\
\hline $8.5 \%$ & $0.5 \%$ \\
\hline $8.8 \%$ & $0.5 \%$ \\
\hline $8.8 \%$ & $0.5 \%$ \\
\hline $8.9 \%$ & $0.5 \%$ \\
\hline $8.9 \%$ & $0.5 \%$ \\
\hline $8.9 \%$ & $0.5 \%$ \\
\hline
\end{tabular}

\begin{tabular}{|c|c|c|}
\hline $\mathbf{u ~ H 3}$ & u MFR 2 & u H2 \\
\hline 4.0 & 0.25 & 257.51 \\
\hline 4.0 & 0.14 & 43.64 \\
\hline 4.0 & 0.12 & 116.06 \\
\hline 4.0 & 0.26 & 262.90 \\
\hline 4.0 & 0.22 & 943.97 \\
\hline 4.0 & 0.18 & 306.35 \\
\hline
\end{tabular}

\begin{tabular}{|c|c|c|}
\hline u H3 / H3 \% & u MFR 2 I MFR 2 $\%$ & u H2 I H2 $\%$ \\
\hline $2.9 \%$ & $14.1 \%$ & $15.3 \%$ \\
\hline $2.9 \%$ & $5.0 \%$ & $7.3 \%$ \\
\hline $2.7 \%$ & $9.3 \%$ & $10.7 \%$ \\
\hline $3.1 \%$ & $14.8 \%$ & $16.2 \%$ \\
\hline $3.2 \%$ & $30.3 \%$ & $31.1 \%$ \\
\hline $2.9 \%$ & $16.1 \%$ & $17.2 \%$ \\
\hline
\end{tabular}




\section{$\underline{\text { Enthalpy Pipe - Initial Design }}$}

The table below involves calculation data involving heat loss estimations through the insulation and through conduction along the pipe wall. The ave $h$ value corresponds to the average convection heat transfer coefficient for the length of the pipe flow. Tw min is the estimated wall temperature at the heated/insulated section inlet. Tw max is the estimated wall temperature at the heated/insulated section outlet. These temperatures are listed in degrees F. Qinsulation is the estimated heat loss through the insulation. Tave is the average wall temperature in Kelvin that was used to evaluate the physical properties of the pipe. The ave k columns are the average thermal conductivity values for the pipe wall in SI units and standard English units (eng). Qpipe is the estimated heat loss due to axial conduction along the pipe wall.

\begin{tabular}{|c|c|c|c|c|}
\hline $\begin{array}{c}\text { BTU/hr/sq ft } \\
R\end{array}$ & & & BTU/hr & \\
\hline ave $h$ & Tw min & $\begin{array}{c}\text { Tw } \\
\max \end{array}$ & Qinsulation & $\begin{array}{c}\text { Tave } \\
\text { (K) }\end{array}$ \\
\hline 247 & 95.2 & 108.2 & 0.11 & 311.7 \\
\hline 221 & 96.1 & 114.7 & 0.12 & 313.8 \\
\hline 214 & 96.4 & 117.7 & 0.13 & 314.7 \\
\hline 201 & 96.3 & 122.0 & 0.14 & 315.9 \\
\hline 190 & 96.6 & 129.8 & 0.16 & 318.1 \\
\hline 181 & 96.5 & 138.4 & 0.19 & 320.5 \\
\hline 167 & 96.5 & 168.1 & 0.26 & 328.7 \\
\hline
\end{tabular}

\begin{tabular}{|c|c|}
\hline ave $\mathbf{k}(\mathbf{S I})$ & $\begin{array}{c}\text { ave } \\
\mathbf{k}(\mathbf{e n g})\end{array}$ \\
\hline 114 & 213 \\
\hline 114 & 214 \\
\hline 114 & 214 \\
\hline 115 & 215 \\
\hline 115 & 216 \\
\hline 116 & 217 \\
\hline 118 & 220 \\
\hline & $\mathrm{BTU} / \mathrm{hr} / \mathrm{ft}$ \\
$\mathrm{W} / \mathrm{m} \mathrm{K}$ & \\
\hline
\end{tabular}

\begin{tabular}{|c|}
\hline Qpipe \\
\hline 0.30 \\
\hline 0.43 \\
\hline 0.50 \\
\hline 0.60 \\
\hline 0.78 \\
\hline 0.99 \\
\hline 1.71 \\
\hline BTU/hr \\
\hline
\end{tabular}

The table on the following page contains data involved in the results and uncertainty analysis. The table is split into four levels. The first level contains raw data. The second level contains calculation and conversions of the raw data. Q is the estimated heat input into the pipe flow. Del $\mathrm{H}$ is the change in enthalpy calculated through an energy balance. Del $\mathrm{H}$ book is the change in enthalpy determined from thermodynamic property tables. The third level contains uncertainty associated with the values directly above them. The fourth level contains uncertainty expressed as a percentage of the second level values. 


\begin{tabular}{|c|c|c|c|c|c|c|c|}
\hline & Flow Reading (mm) & $\begin{array}{c}\text { Flow } \\
\mathbf{( c c / m i n})\end{array}$ & $\mathbf{Q}$ (Watts) & T1 (F) & $\begin{array}{c}\text { P1 } \\
\text { (psig) }\end{array}$ & $\begin{array}{c}\text { T2 } \\
\text { (F) }\end{array}$ & $\begin{array}{c}\text { P2 } \\
\text { (psig) }\end{array}$ \\
\hline $\mathbf{1}$ & 140 & 1242 & 687.7 & 83.9 & 21.0 & 96.9 & 16.5 \\
\hline $\mathbf{2}$ & 104 & 857 & 687.7 & 83.6 & 25.5 & 102.2 & 22.0 \\
\hline $\mathbf{3}$ & 93 & 751 & 687.7 & 83.5 & 19.5 & 104.8 & 16.0 \\
\hline $\mathbf{4}$ & 76 & 587 & 687.7 & 83.3 & 28.0 & 109.0 & 24.0 \\
\hline $\mathbf{5}$ & 60 & 448 & 687.7 & 83.0 & 18.0 & 116.2 & 14.0 \\
\hline $\mathbf{6}$ & 50 & 354 & 687.7 & 82.3 & 17.0 & 124.2 & 13.5 \\
\hline $\mathbf{7}$ & 30 & 198 & 687.7 & 81.8 & 24.0 & 153.4 & 20.0 \\
\hline
\end{tabular}

\begin{tabular}{|l|c|c|c|c|}
\hline & $\begin{array}{c}\text { Mass Flow Rate } \\
\text { (Ibm/hr) }\end{array}$ & Q (Btu/hr) & $\begin{array}{c}\text { del H } \\
\text { (Btu/lbm) }\end{array}$ & $\begin{array}{c}\text { del H } \\
\text { book }\end{array}$ \\
\hline $\mathbf{1}$ & 163.7 & 2347 & 14.34 & 12.98 \\
\hline $\mathbf{2}$ & 112.9 & 2347 & 20.78 & 18.56 \\
\hline $\mathbf{3}$ & 99.0 & 2347 & 23.72 & 21.26 \\
\hline $\mathbf{4}$ & 77.4 & 2347 & 30.34 & 25.64 \\
\hline $\mathbf{5}$ & 59.0 & 2347 & 39.76 & 33.13 \\
\hline $\mathbf{6}$ & 46.6 & 2347 & 50.32 & 41.81 \\
\hline $\mathbf{7}$ & 26.1 & 2347 & 89.96 & 71.48 \\
\hline
\end{tabular}

\begin{tabular}{|c|c|c|c|}
\hline & Uncertainty (lbm/hr) & Q unc. & H unc. \\
\hline $\mathbf{1}$ & 9.0 & 241 & 1.67 \\
\hline $\mathbf{2}$ & 9.0 & 241 & 2.70 \\
\hline $\mathbf{3}$ & 9.0 & 241 & 3.25 \\
\hline $\mathbf{4}$ & 9.0 & 241 & 4.70 \\
\hline $\mathbf{5}$ & 9.0 & 241 & 7.29 \\
\hline $\mathbf{6}$ & 9.0 & 241 & 10.96 \\
\hline $\mathbf{7}$ & 9.0 & 241 & 32.25 \\
\hline
\end{tabular}

\begin{tabular}{|l|c|c|c|}
\hline & u mdot / $\mathbf{~ m o t} \%$ & $\mathbf{u} \mathbf{Q} / \mathbf{Q} \%$ & $\mathbf{u} \mathbf{H} / \mathbf{H} \%$ \\
\hline $\mathbf{1}$ & $5.5 \%$ & $10.3 \%$ & $11.6 \%$ \\
\hline $\mathbf{2}$ & $7.9 \%$ & $10.3 \%$ & $13.0 \%$ \\
\hline $\mathbf{3}$ & $9.1 \%$ & $10.3 \%$ & $13.7 \%$ \\
\hline $\mathbf{4}$ & $11.6 \%$ & $10.3 \%$ & $15.5 \%$ \\
\hline $\mathbf{5}$ & $15.2 \%$ & $10.3 \%$ & $18.3 \%$ \\
\hline $\mathbf{6}$ & $19.2 \%$ & $10.3 \%$ & $21.8 \%$ \\
\hline $\mathbf{7}$ & $34.3 \%$ & $10.3 \%$ & $35.8 \%$ \\
\hline
\end{tabular}




\section{Enthalpy Pipe - Future Design}

The organization of the "Future Design" table is the same as the "Initial Design" table. The heat loss estimations stated in the "Initial Design" section also apply to the future design. The difference in these tables is located in the uncertainty values.

\begin{tabular}{|c|c|c|c|c|c|c|c|}
\hline & Flow Reading (mm) & $\begin{array}{c}\text { Flow } \\
\text { (cc/min) }\end{array}$ & $\mathbf{Q}$ (Watts) & T1 (F) & $\begin{array}{c}\text { P1 } \\
\text { (psig) }\end{array}$ & $\begin{array}{c}\text { T2 } \\
\mathbf{( F )}\end{array}$ & $\begin{array}{c}\text { P2 } \\
\text { (psig) }\end{array}$ \\
\hline $\mathbf{1}$ & 140 & 1242 & 687.7 & 83.9 & 21.0 & 96.9 & 16.5 \\
\hline $\mathbf{2}$ & 104 & 857 & 687.7 & 83.6 & 25.5 & 102.2 & 22.0 \\
\hline $\mathbf{3}$ & 93 & 751 & 687.7 & 83.5 & 19.5 & 104.8 & 16.0 \\
\hline $\mathbf{4}$ & 76 & 587 & 687.7 & 83.3 & 28.0 & 109.0 & 24.0 \\
\hline $\mathbf{5}$ & 60 & 448 & 687.7 & 83.0 & 18.0 & 116.2 & 14.0 \\
\hline $\mathbf{6}$ & 50 & 354 & 687.7 & 82.3 & 17.0 & 124.2 & 13.5 \\
\hline $\mathbf{7}$ & 30 & 198 & 687.7 & 81.8 & 24.0 & 153.4 & 20.0 \\
\hline
\end{tabular}

\begin{tabular}{|c|c|c|c|c|}
\hline & $\begin{array}{c}\text { Mass Flow Rate } \\
\text { (Ibm/hr) }\end{array}$ & Q (Btu/hr) & $\begin{array}{c}\text { del H } \\
\text { (Btu/lbm) }\end{array}$ & $\begin{array}{c}\text { del H } \\
\text { book }\end{array}$ \\
\hline $\mathbf{1}$ & 163.7 & 2347 & 14.34 & 12.98 \\
\hline $\mathbf{2}$ & 112.9 & 2347 & 20.78 & 18.56 \\
\hline $\mathbf{3}$ & 99.0 & 2347 & 23.72 & 21.26 \\
\hline $\mathbf{4}$ & 77.4 & 2347 & 30.34 & 25.64 \\
\hline $\mathbf{5}$ & 59.0 & 2347 & 39.76 & 33.13 \\
\hline $\mathbf{6}$ & 46.6 & 2347 & 50.32 & 41.81 \\
\hline $\mathbf{7}$ & 26.1 & 2347 & 89.96 & 71.48 \\
\hline
\end{tabular}

\begin{tabular}{|c|c|c|c|}
\hline & Uncertainty (lbm/hr) & $\mathbf{Q}$ unc. & H unc. \\
\hline $\mathbf{1}$ & 3.3 & 12.3 & 0.30 \\
\hline $\mathbf{2}$ & 2.3 & 12.3 & 0.43 \\
\hline $\mathbf{3}$ & 2.0 & 12.3 & 0.49 \\
\hline $\mathbf{4}$ & 1.5 & 12.3 & 0.63 \\
\hline $\mathbf{5}$ & 1.2 & 12.3 & 0.82 \\
\hline $\mathbf{6}$ & 0.9 & 12.3 & 1.04 \\
\hline $\mathbf{7}$ & 0.5 & 12.3 & 1.86 \\
\hline
\end{tabular}

\begin{tabular}{|l|c|c|c|}
\hline & u mdot / $\mathbf{~ m d o t ~} \%$ & $\mathbf{u} \mathbf{Q} / \mathbf{Q} \%$ & $\mathbf{u} \mathbf{~} / \mathbf{H} \%$ \\
\hline $\mathbf{1}$ & $2.0 \%$ & $0.5 \%$ & $2.1 \%$ \\
\hline $\mathbf{2}$ & $2.0 \%$ & $0.5 \%$ & $2.1 \%$ \\
\hline $\mathbf{3}$ & $2.0 \%$ & $0.5 \%$ & $2.1 \%$ \\
\hline $\mathbf{4}$ & $2.0 \%$ & $0.5 \%$ & $2.1 \%$ \\
\hline $\mathbf{5}$ & $2.0 \%$ & $0.5 \%$ & $2.1 \%$ \\
\hline $\mathbf{6}$ & $2.0 \%$ & $0.5 \%$ & $2.1 \%$ \\
\hline $\mathbf{7}$ & $2.0 \%$ & $0.5 \%$ & $2.1 \%$ \\
\hline
\end{tabular}




\section{Appendix D - Uncertainty Analysis}

\section{Propagation of Uncertainty}

The uncertainty of a function, $f$, with independent variables $x_{1}, x_{2}, x_{3}, \ldots$, which have uncertainties of $u_{1}, u_{2}, u_{3}, \ldots$ is $u_{f}$.

$u_{f}=\sqrt{\left(\frac{\partial f}{\partial x_{1}} u_{1}\right)^{2}+\left(\frac{\partial f}{\partial x_{2}} u_{2}\right)^{2}+\left(\frac{\partial f}{\partial x_{3}} u_{3}\right)^{2}+\Lambda}$

\section{Heat Exchanger}

This section is a walkthrough of the entire uncertainty analysis performed on a set of readings from the initial design of the heat exchanger experiment.

Mass Flow Rate Uncertainty of Spray and Exit Streams

$$
\dot{m}=0.13368 \dot{V} \rho
$$

Applying (A.2) to (A.1) results in the mass flow rate uncertainty (A.3)

$$
u_{\dot{m}}=\sqrt{\left(0.13368 \rho u_{\dot{V}}\right)^{2}+\left(0.13368 \dot{V} u_{\rho}\right)^{2}}
$$

Mass Flow Rate Uncertainty of Steam

$$
\dot{m}_{2}=\dot{m}_{3}-\dot{m}_{1}
$$

Applying (A.4) to (A.1) results in the steam mass flow rate uncertainty (A.5)

$$
u_{m_{2}}=\sqrt{\left(u_{m_{3}}\right)^{2}+\left(-u_{m_{1}}\right)^{2}}
$$

Uncertainty of Steam Enthalpy

$$
H_{2}=\frac{\dot{Q}_{\text {loss }}+\dot{m}_{3} H_{3}-\dot{m}_{1} H_{1}}{\dot{m}_{2}}
$$

Applying (A.6) to (A.1) results in the uncertainty of the steam enthalpy (A.7) 


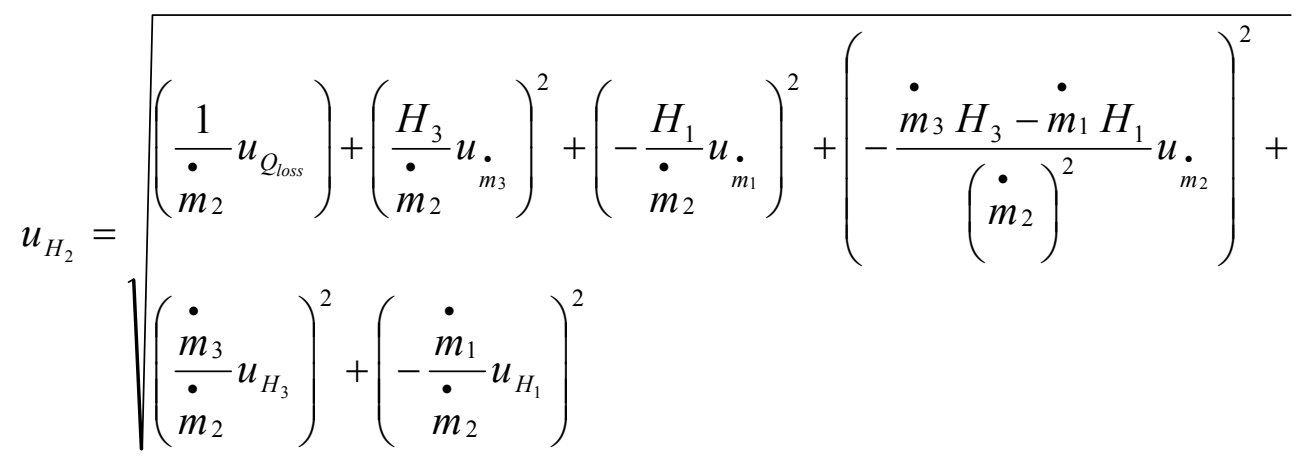

(A.7)

\section{Enthalpy Pipe}

This section is a walkthrough of the entire uncertainty analysis performed on a set of readings from the initial design of the enthalpy pipe experiment.

Mass Flow Rate Uncertainty

$$
\dot{m}=0.061024 \frac{60}{1728} \dot{V} \rho
$$

Applying (A.8) to (A.1) results in the mass flow rate uncertainty (A.9)

$$
u_{\dot{m}}=\sqrt{\left(0.061024 \frac{60}{1728} \rho u_{\dot{V}}\right)^{2}+\left(0.061024 \frac{60}{1728} \dot{V} u_{\rho}\right)^{2}}
$$

\section{Heat Input Rate}

$$
\dot{Q}=\frac{\varepsilon^{2}}{\Omega}
$$

Applying (A.10) to (A.1) results in uncertainty of the heat input rate (A.11)

$$
u_{\dot{Q}}=\sqrt{\left(\frac{2 \varepsilon}{\Omega} u_{\varepsilon}\right)^{2}+\left(-\frac{\varepsilon^{2}}{\Omega^{2}} u_{\Omega}\right)^{2}}
$$

Change in Enthalpy

$$
\Delta H=\frac{\dot{Q}}{\dot{m}}
$$


Applying (A.11) to (A.1) results in the uncertainty of the change in enthalpy (A.13)

$$
u_{\Delta H}=\sqrt{\left(\frac{1}{\dot{m}} u_{\dot{Q}}\right)^{2}+\left(-\frac{\dot{Q}}{\dot{m}^{2}} u_{\dot{m}}\right)^{2}}
$$




\section{Appendix E - Flowmeter Calibration Data for Water}

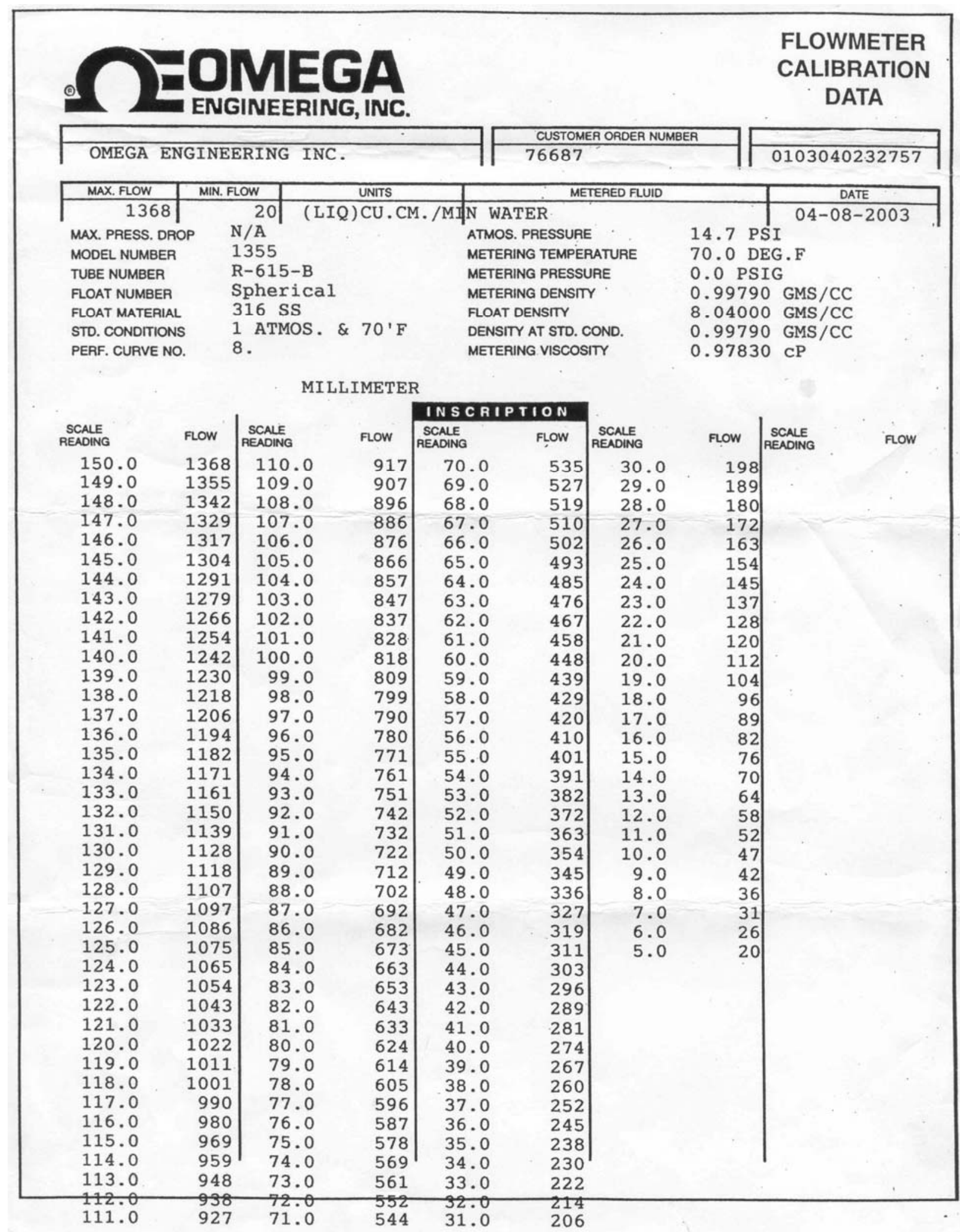




\section{Appendix F - Flowmeter Calibration Data for Air}

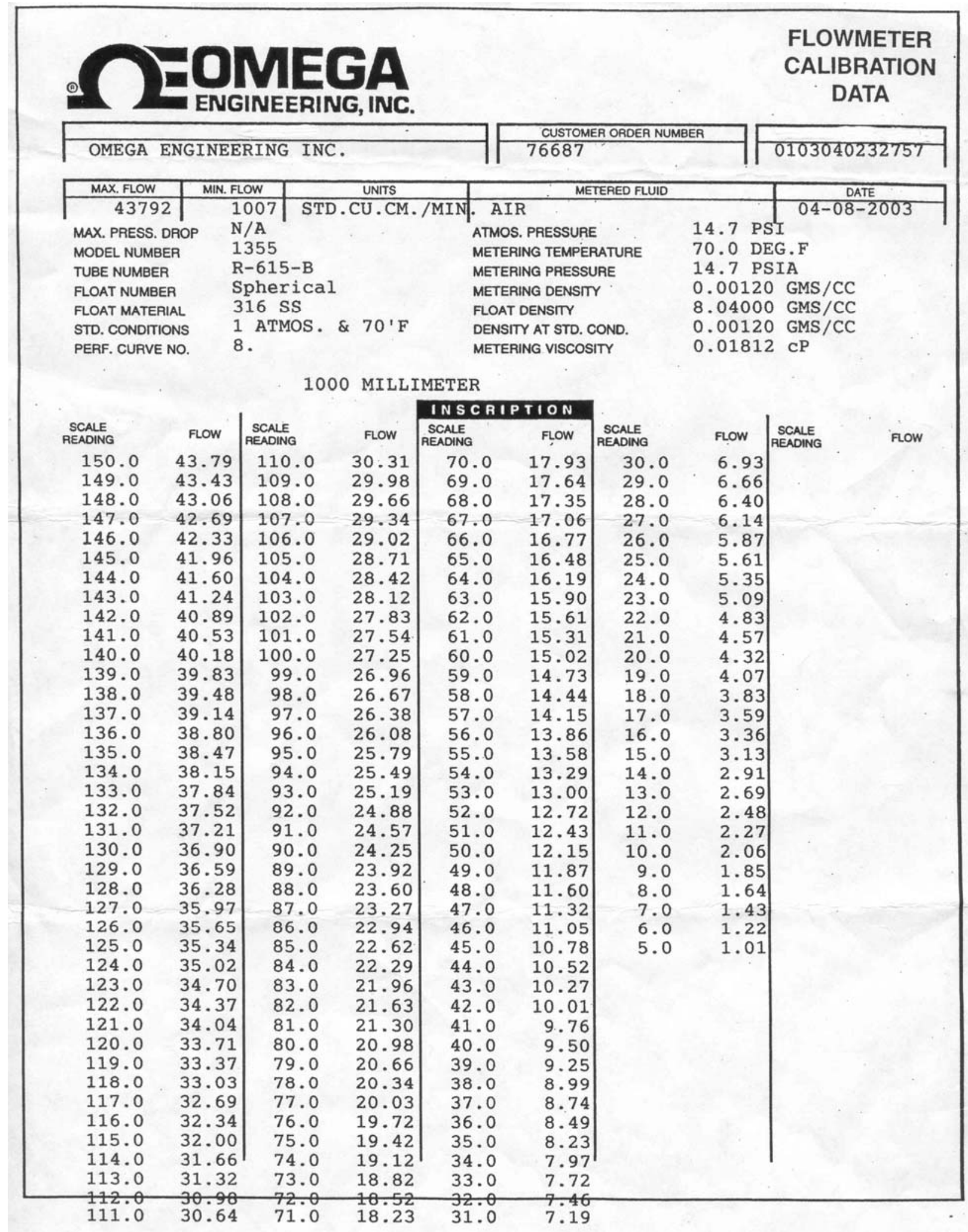

